\title{
Inherited Congenital Cataract: A Guide to Suspect the Genetic Etiology in the Cataract Genesis
}

\author{
Olga Messina-Baas ${ }^{a}$ Sergio A. Cuevas-Covarrubias ${ }^{b}$ \\ Departments of a Ophthalmology and ${ }^{\mathrm{b}}$ Medical Genetics, Facultad de Medicina, Hospital General de México, \\ UNAM, Mexico City, Mexico
}

\section{Keywords \\ Clinical heterogeneity $\cdot$ Clinical variability $\cdot$ Congenital cataract $\cdot$ Genetic heterogeneity}

\begin{abstract}
Cataracts are the principal cause of treatable blindness worldwide. Inherited congenital cataract (CC) shows all types of inheritance patterns in a syndromic and nonsyndromic form. There are more than 100 genes associated with cataract with a predominance of autosomal dominant inheritance. A cataract is defined as an opacity of the lens producing a variation of the refractive index of the lens. This variation derives from modifications in the lens structure resulting in light scattering, frequently a consequence of a significant concentration of high-molecular-weight protein aggregates. The aim of this review is to introduce a guide to identify the gene involved in inherited CC. Due to the manifold clinical and genetic heterogeneity, we discarded the cataract phenotype as a cardinal sign; a 4-group classification with the genes implicated in inherited CC is proposed. We consider that this classification will assist in identifying the probable gene involved in inherited CC.
\end{abstract}

(c) 2017 S. Karger AG, Basel

\section{KARGER}

(c) 2017 S. Karger AG, Basel

E-Mail karger@karger.com

www.karger.com/msy
Cataracts cause half of all cases of blindness and onethird of the visual impairment cases worldwide. The term cataract comes from the Latin word "cataracta" that itself derives from the Greek "katarráktés" and refers to a waterfall. Apparently, Constantine the African (a Carthaginian monk from the Monte Cassino monastery and a member of the Salerno school of translators) borrowed this term for lens opacity from the translation of Arab medical writings into Latin. Cataract is a term that is still used today [Chance, 1939]. Since cataracts are the most common cause of vision loss in the world, surgical management of this has been documented since ancient times. Possibly, the first written evidence is from 600 years B.C.: "Uttara-Tantra of Sushruta Samshita," wherein the recline method technique is described [Bhishagratna, 2005].

A cataract is defined as an opacity of the lens resulting from a variation of the refractive index of the lens. This variation derives from changes in the lens structure resulting in light scattering, frequently due to a significant concentration of high-molecular-weight protein aggregates. Congenital cataract (CC), one of the leading causes of treatable blindness worldwide, has a prevalence of 1-15/ 10,000 live births with a greater presence in developing countries than in developed countries [Apple et al., 2000;

Dr. Sergio A. Cuevas-Covarrubias 

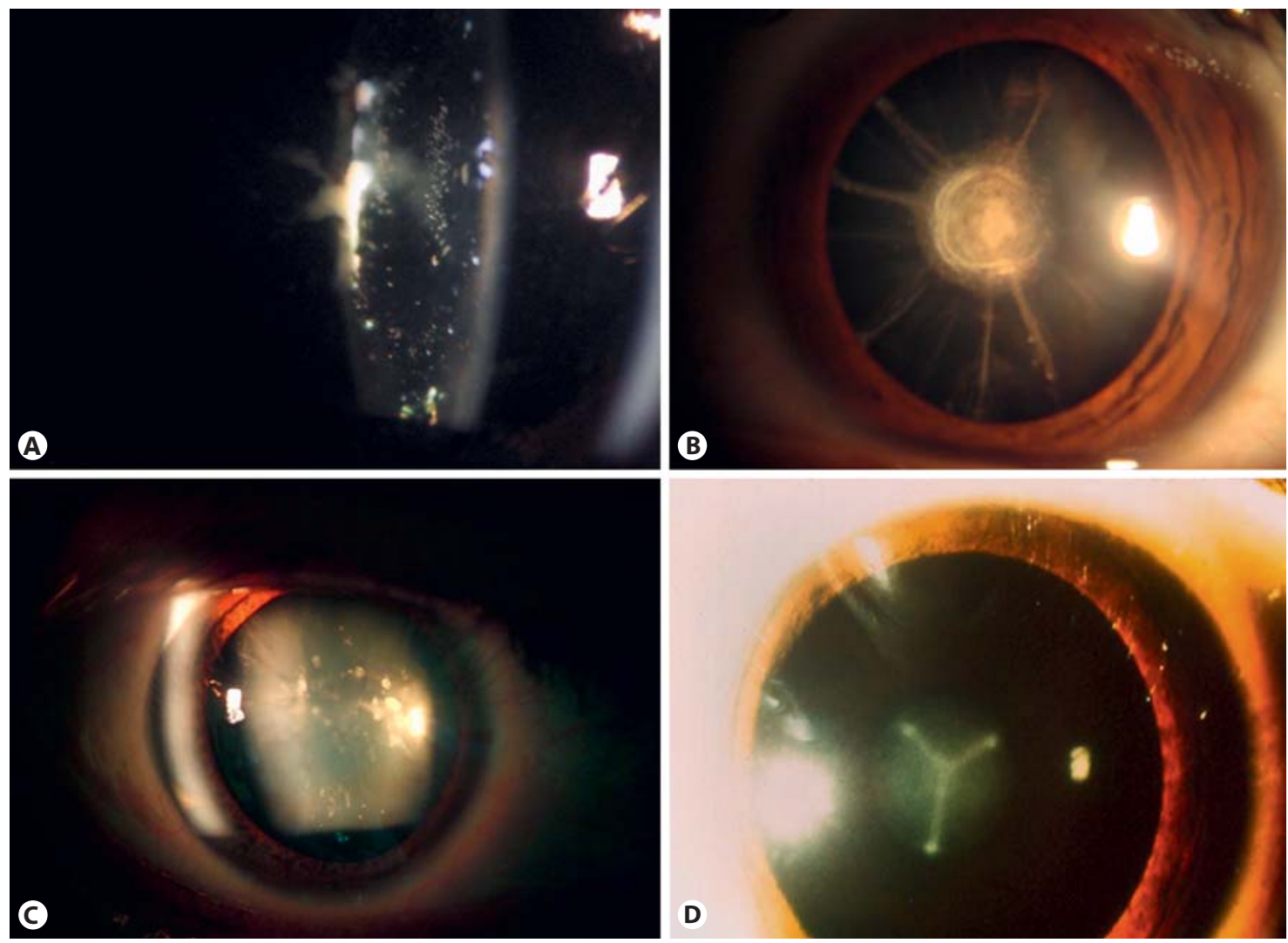

Fig. 1. Some examples of inherited cataracts: anterior subcapsular (A), fetal nuclear (B), punctate in lens cortex (C), and embryonic nuclear Y-sutural (D).

Gilbert and Foster, 2001]. Inherited CC is a clinically and genetically heterogeneous disease normally associated with the breakdown of the lens architecture. Inherited CC presents all types of inheritance patterns in a syndromic and nonsyndromic form with more than 100 causative genes (http://cat-map.wustl.edu/). For example, hereditary CC may be inherited as autosomal dominant, autosomal recessive, or X-linked traits, with autosomal dominant being the most prevalent form of inheritance pattern. Hereditary CC shows an important intrafamilial and interfamilial variability; the same mutation in one gene can result in distinct cataract phenotypes, whereas expression of different genes can produce the same cataract pattern. Clinical variability can even be observed in the same patient [Hejtmancik and Smaoui, 2003].

Several terms have been used to describe the different types of hereditary CC in the literature. CC classification has not been homogenous. In some cases, the description corresponds to the name of the author who first described the cataract, i.e., Marner cataract, a cataract with sutural opacities [Marner et al., 1989]; to the name of the affected family such as Coppock cataract, an embryonic nuclear cataract [Nettleship and Ogilvie, 1906]; the Volkman cataract, a central or zonular variety with opacities in the embryonic, fetal, and juvenile nucleus [Eiberg 1995], or to the affected community such as the Hutterite cataract [Boone et al., 2015]. In other cases, anatomic localization is used to establish the cataract definition, i.e., subcapsular, nuclear, sutural, cortical, fetal, embryonic, or capsular cataract (Fig. 1).

There are excellent reviews of inherited cataracts in the literature. The purpose of this review is to provide a guide to the suspected genetic causes of inherited CC. Due to the great clinical and genetic heterogeneity, we separated the genes implicated in the process of cataractogenesis into 4 groups (Tables 1-4). These groups contain the genes involved in syndromic cataracts, the genes implicated in syndromic cataracts but with reports of congenital cataracts only, the genes that present cataracts only, and finally, the genes with cataract and eye anomalies. We consider that this classification will assist in identifying the probable gene involved in inherited CC. 
Table 1. Syndromic cataract genes

\begin{tabular}{|c|c|c|c|c|c|}
\hline Locus & Gene & Inheritance & OMIM & Disease & Gene product \\
\hline $1 \mathrm{p} 36.32$ & PEX10 & AR & 614870 & neonatal adrenoleukodystrophy, Zellweger syndrome & protein of peroxisomal matrix \\
\hline $1 \mathrm{p} 36.22$ & PEX14 & AR & 614887 & Zellweger syndrome & peroxisomal import machinery \\
\hline $1 \mathrm{p} 36.1 \mathrm{p} 34$ & HSPG2 & $\mathrm{AR}$ & $224410 / 25800$ & $\begin{array}{l}\text { Schwartz-Jampel syndrome type } 1 / \text { dyssegmental } \\
\text { dysplasia }\end{array}$ & perlecan protein \\
\hline $1 \mathrm{p} 36 \mathrm{p} 35$ & GALE & AR & 230350 & galactose epimerase deficiency & UDP-galactose-4-epimerase \\
\hline $1 \mathrm{p} 34.1$ & POMGNT1 & $\mathrm{AR}$ & 253280 & muscular dystrophy-dystroglycanopathy & $\begin{array}{l}\text { type } 2 \text { transmembrane protein that resides in the Golgi } \\
\text { apparatus }\end{array}$ \\
\hline $1 \mathrm{p} 22 \mathrm{p} 21$ & $A B C D 3$ & $\mathrm{AR}$ & 616278 & Zellweger syndrome 2 & $\begin{array}{l}\text { member of the superfamily of ATP-binding cassette } \\
\text { transporters }\end{array}$ \\
\hline $1 \mathrm{p} 21$ & COL11A1 & $\mathrm{AD}$ & $604841 / 154780$ & Stickler syndrome type 2, Marshall syndrome & one of the 2 alpha chains of type XI collagen \\
\hline $1 \mathrm{q} 41$ & IARS2 & $\mathrm{AR}$ & 616007 & $\begin{array}{l}\text { cataracts, growth hormone deficiency, sensory } \\
\text { neuropathy, sensorineural hearing loss, skeletal } \\
\text { dysplasia }\end{array}$ & Aminoacyl-tRNA synthetase \\
\hline $1 \mathrm{q} 41$ & RAB3GAP2 & $\mathrm{AR}$ & $212720 / 614225$ & Martsolf syndrome, Warburg micro syndrome & $\begin{array}{l}\text { RAB3 protein regulates exocytosis of neurotransmitters and } \\
\text { hormones }\end{array}$ \\
\hline $1 \mathrm{q} 42$ & GNPAT & $\mathrm{AR}$ & 222765 & rhizomelic chondrodysplasia punctata type 2 & enzyme in synthesis of ether phospholipids \\
\hline 2p14p16 & PEX13 & AR & 614883 & Zellweger syndrome & peroxisomal membrane protein \\
\hline $2 \mathrm{q} 21.3$ & $R A B 3 G A P 1$ & AR & 600118 & Warburg micro syndrome & catalytic subunit of a Rab GTPase activating protein \\
\hline $2 \mathrm{q} 24 \mathrm{q} 31$ & $L R P 2$ & AR & 222448 & Donnai-Barrow syndrome & low density lipoprotein-related protein 2 \\
\hline 2q33qter & CYP27A1 & AR & 213700 & cerebrotendinous xanthomatosis & member of the cytochrome P450 superfamily \\
\hline $2 \mathrm{q} 37$ & KCNJ13 & $\mathrm{AD}$ & 193230 & snowflake vitreoretinal degeneration & member of the inwardly rectifying potassium channel family \\
\hline $3 \mathrm{p} 21.1$ & COL7A1 & AR & 226600 & epidermolysis bullosa dystrophica & alpha chain of type VII collagen \\
\hline 3 p 14.3 & $F L N B$ & $\mathrm{AD}, \mathrm{AR}$ & $150250 / 272460$ & $\begin{array}{l}\text { Larsen syndrome/spondylocarpotarsal synostosis } \\
\text { syndrome }\end{array}$ & member of the filamin family \\
\hline $3 q 21 q 22$ & $C N B P$ & $\mathrm{AD}$ & 602668 & myotonic dystrophy type 2 & a nucleic-acid binding protein with 7 zinc-finger domains \\
\hline $3 q 25$ & SLC33A1 & AR & 614482 & congenital cataracts, hearing loss, neurodegeneration & required for the formation of $\mathrm{O}$-acetylated (Ac) gangliosides \\
\hline $4 \mathrm{p} 16.1$ & $H M X 1$ & $\mathrm{AR}$ & 612109 & oculoauricular syndrome & $\begin{array}{l}\text { transcription factor that belongs to the } \mathrm{H} 6 \text { family of } \\
\text { homeobox proteins }\end{array}$ \\
\hline $4 \mathrm{p} 15.32$ & $C C 2 D 2 A$ & AR & 612285 & Joubert syndrome 9 & play a critical role in cilia formation \\
\hline $4 \mathrm{p} 12 \mathrm{q} 12$ & SRD5A3 & AR & 612713 & Kahirazi syndrome & steroid 5-alpha reductase family \\
\hline $4 \mathrm{q} 32 \mathrm{q} 35$ & ETFDH & AR & 231680 & glutaric acidemia & component of the electron-transfer system in mitochondria \\
\hline $4 q 35.1$ & TRAPPC11 & AR & 615356 & muscular dystrophy limb girdle $2 \mathrm{~S}$ & $\begin{array}{l}\text { a subunit of the TRAPP (transport protein particle) } \\
\text { tethering complex }\end{array}$ \\
\hline $5 q 12.1$ & ERCC8 & AR & 216400 & Cockayne syndrome type A & a WD repeat protein \\
\hline $5 q 14.3$ & VCAN & $\mathrm{AD}$ & 143200 & Wagner syndrome 1 & a member of the aggrecan/versican proteoglycan family \\
\hline $5 q 31$ & SIL1 & $\mathrm{AR}$ & 248800 & Marinesco-Sjögren syndrome & resident endoplasmic reticulum $\mathrm{N}$-linked glycoprotein \\
\hline $6 \mathrm{p} 24$ & TFAP $2 A$ & $\mathrm{AD}$ & 113620 & branchiooculofacial syndrome & a transcription factor \\
\hline $6 \mathrm{p} 23$ & GCM2 & $\mathrm{AD}$ & 146200 & hypoparathyroidism familial isolated & a homolog of the Drosophila glial cells missing gene \\
\hline $6 \mathrm{p} 21.3$ & NEU1 & $\mathrm{AR}$ & 256550 & sialidosis type 2 & a lysosomal enzyme that cleaves terminal sialic acid residues \\
\hline $6 \mathrm{q} 21 \mathrm{q} 23.2$ & GJA1 & $\mathrm{AD}$ & 164200 & oculodentodigital dysplasia & a member of the connexin gene family \\
\hline $6 \mathrm{q} 22 \mathrm{q} 24$ & PEX7 & AR & 215100 & rhizomelic chondrodysplasia punctata type 1 & cytosolic receptor for the set of peroxisomal matrix enzymes \\
\hline $6 \mathrm{q} 24.2$ & PEX3 & AR & 614882 & Zellweger syndrome & involved in peroxisome biosynthesis and integrity \\
\hline $7 \mathrm{p} 15.3$ & FAM126A & AR & 610532 & hypomyelinating leukodystrophy 5 & part in the beta-catenin/Lef signaling pathway \\
\hline $7 \mathrm{q} 21.2$ & PEX1 & $\mathrm{AR}$ & 214100 & Zellweger syndrome & a member of the AAA ATPase family \\
\hline $7 \mathrm{q} 31.1$ & $C A V 1$ & $\mathrm{AD}$ & 606721 & $\begin{array}{l}\text { partial lipodystrophy, congenital cataracts, } \\
\text { neurodegeneration syndrome }\end{array}$ & main component of the caveolae plasma membranes \\
\hline $7 \mathrm{q} 34$ & $A G K$ & $\mathrm{AR}$ & 212350 & Sengers syndrome & $\begin{array}{l}\text { a mitochondrial membrane protein involved in lipid and } \\
\text { glycerolipid metabolism }\end{array}$ \\
\hline $8 \mathrm{p} 21.1$ & ESCO2 & AR & 268300 & Roberts syndrome & $\begin{array}{l}\text { acetyltransferase activity may be required for the } \\
\text { establishment of sister chromatid cohesion }\end{array}$ \\
\hline $8 \mathrm{q} 13.3$ & EYA1 & $\mathrm{AD}$ & 601653 & branchiootorenal syndrome 1 & a member of the eyes absent (EYA) family of proteins \\
\hline $8 \mathrm{q} 21.1$ & PXMP3 & $\mathrm{AR}$ & 614866 & Zellweger syndrome & $\begin{array}{l}\text { an integral peroxisomal membrane protein required for } \\
\text { peroxisome biogenesis }\end{array}$ \\
\hline $8 \mathrm{q} 21 \mathrm{q} 22$ & CNGB3 & AR & 262300 & achromatopsia 3 & the beta subunit of a cyclic nucleotide-gated ion channel \\
\hline $8 \mathrm{q} 24.3$ & RECQL4 & AR & 268400 & Rothmund Thompson syndrome & DNA helicase that belongs to the RecQ helicase family \\
\hline $9 \mathrm{p} 13.13$ & GALT & AR & 230400 & galatosemia & galactose-1-phosphate uridyl transferase \\
\hline $9 \mathrm{p} 24$ & $V L D L R$ & AR & 224050 & $\begin{array}{l}\text { cerebellar hypoplasia and mental retardation with or } \\
\text { without quadrupedal locomotion } 1\end{array}$ & low-density lipoprotein receptor \\
\hline $9 q 31 q 33$ & FKTN & AR & 253800 & muscular dystrophy-dystroglycanopathy & $\begin{array}{l}\text { a putative transmembrane protein localized to the cis-Golgi } \\
\text { compartment }\end{array}$ \\
\hline $9 \mathrm{q} 34$ & $L M X 1 B$ & $\mathrm{AD}$ & 161200 & nail-patella syndrome & a member of LIM-homeodomain family of proteins \\
\hline $9 q 34.1$ & POMT1 & $\mathrm{AR}$ & 236670 & muscular dystrophy-dystroglycanopathy A1 & an O-mannosyltransferase \\
\hline $10 q 11.23$ & ERCC6 & AR & $214150 / 133540$ & $\begin{array}{l}\text { cerebrooculofacioskeletal syndrome I/Cockayne } \\
\text { syndrome type B }\end{array}$ & $\begin{array}{l}\text { a DNA-binding protein that is important in } \\
\text { transcription-coupled excision repair }\end{array}$ \\
\hline $10 \mathrm{q} 23.31$ & PTEN & $\mathrm{AD}$ & 158350 & Cowden disease & a tumor suppressor \\
\hline $10 \mathrm{q} 24.3$ & ALDH18A1 & $\mathrm{AD} / \mathrm{AR}$ & $616603 / 219150$ & cutis laxa $\mathrm{AD} /$ cutis laxa $\mathrm{AR}$ & a member of the aldehyde dehydrogenase family \\
\hline $10 \mathrm{q} 26$ & $O A T$ & $\mathrm{AR}$ & 258870 & gyrate atrophy of choroid and retina & mitochondrial enzyme ornithine aminotransferase \\
\hline
\end{tabular}


Table 1 (continued)

\begin{tabular}{|c|c|c|c|c|c|}
\hline Locus & Gene & Inheritance & OMIM & Disease & Gene product \\
\hline $11 \mathrm{p} 15.3 \mathrm{p} 15.1$ & PTH & $\mathrm{AD} / \mathrm{AR}$ & 146200 & familial isolated hypoparathyroidism & a member of the parathyroid family of proteins \\
\hline $11 \mathrm{q} 13.4$ & LRP5 & $\mathrm{AR}, \mathrm{AD}$ & $601813 / 607634$ & $\begin{array}{l}\text { exudative vitreoretinopathy } 4 \text { /osteopetrosis, } \\
\text { autosomal dominant } 1\end{array}$ & a transmembrane low-density lipoprotein receptor \\
\hline $11 \mathrm{q} 13.2 \mathrm{q} 13.5$ & DHCR7 & $\mathrm{AR}$ & 270400 & Smith-Lemli-Opitz syndrome & $\begin{array}{l}\text { an enzyme that removes the } \mathrm{C}(7-8) \text { double bond in the } \\
\mathrm{B} \text { ring of sterols }\end{array}$ \\
\hline $11 \mathrm{q} 13.4$ & $C L P B$ & AR & 616271 & $\begin{array}{l}\text { 3-methylglutaconic aciduria with cataracts, } \\
\text { neurologic involvement, neutropenia }\end{array}$ & $\begin{array}{l}\text { member of the ATPases associated with diverse cellular } \\
\text { activities }(\mathrm{AAA}+) \text { superfamily }\end{array}$ \\
\hline $11 \mathrm{q} 14.2$ & FZD4 & $\mathrm{AD}$ & 133780 & retinopathy of prematurity & a member of the frizzled gene family \\
\hline $11 \mathrm{q} 22.3$ & $M M P 1$ & $\mathrm{AR}$ & 226600 & epidermolysis bullosa dystrophic & $\begin{array}{l}\text { a member of the peptidase M10 family of matrix } \\
\text { metalloproteinases }\end{array}$ \\
\hline $11 \mathrm{q} 22.1 \mathrm{q} 23.2$ & $C R Y A B$ & $\mathrm{AD}$ & 608810 & myofibrillar myopathy & members of the small heat shock protein (HSP20) family \\
\hline $11 \mathrm{q} 23.3$ & $S C 5 D L$ & AR & 607330 & lathosterolosis & enzyme of cholesterol biosynthesis \\
\hline $11 \mathrm{q} 25$ & JAM3 & $\mathrm{AR}$ & 613730 & $\begin{array}{l}\text { hemorrhagic destruction of brain, subependymal } \\
\text { calcification }\end{array}$ & immunoglobulin superfamily gene member \\
\hline $12 q 13.12$ & TUBA1A & $\mathrm{AD}$ & 611603 & lissencephaly & microtubule constituents of to the tubulin superfamily \\
\hline $12 \mathrm{p} 13.3$ & PEX5 & AR & 214110 & Zellweger syndrome & protein essential for the assembly of functional peroxisomes \\
\hline $12 \mathrm{q} 24$ & $M V K$ & $\mathrm{AR}$ & 610377 & mevalonic aciduria & peroxisomal enzyme mevalonate kinase \\
\hline $13 q 12$ & GJB6 & $\mathrm{AD}$ & 129500 & Clouston syndrome & one of the connexin proteins \\
\hline $13 q 12.3$ & $B 3 G A L T L$ & $\mathrm{AR}$ & 261540 & Peters-plus syndrome & $\begin{array}{l}\text { a beta-1,3-glucosyltransferase that transfers glucose to } \\
\text { O-linked fucosylglycans on thrombospondin type- } 1 \text { repeats }\end{array}$ \\
\hline $13 q 14.3$ & ITM2B & $\mathrm{AD}$ & 117300 & cerebral amyloid angiopathy & a transmembrane protein \\
\hline $13 q 34$ & COL4A1 & $\mathrm{AD}$ & 607595 & cerebral small vessel disease & a type IV collagen alpha protein \\
\hline $14 \mathrm{q} 21.1$ & SEC23A & $\mathrm{AR}$ & 607812 & craniolenticulosutural dysplasia & $\begin{array}{l}\text { a member of the SEC23 subfamily of the SEC23/SEC24 } \\
\text { family }\end{array}$ \\
\hline $14 \mathrm{q} 24$ & POMT2 & $\mathrm{AR}$ & 613150 & muscular dystrophy-dystroglycanopathy & an O-mannosyltransferase \\
\hline $15 q 15$ & $B U B 1 B$ & AR & 257300 & mosaic variegated aneuploidy syndrome 1 & a kinase involved in spindle checkpoint function \\
\hline $15 \mathrm{q} 21.1$ & FBN1 & $\mathrm{AD}$ & 608328 & Weill-Marchesani syndrome & a member of the fibrillin family of proteins \\
\hline $15 \mathrm{q} 25$ & $P O L G$ & $\mathrm{AD} / \mathrm{AR}$ & 157640 & $\begin{array}{l}\text { progressive external ophthalmoplegia with } \\
\text { mitochondrial DNA deletions } 1\end{array}$ & the catalytic subunit of mitochondrial DNA polymerase \\
\hline $16 \mathrm{p} 13.3 \mathrm{p} 13.2$ & GFER & $\mathrm{AR} ?$ & 613076 & $\begin{array}{l}\text { progressive mitochondrial myopathy, sensorineural } \\
\text { hearing loss, developmental delay }\end{array}$ & structural and functional homolog of the yeast $s c E R V 1$ gene \\
\hline $16 \mathrm{q} 21$ & NOD2 & $\mathrm{AD}$ & 186580 & Blau syndrome & a member of the Nod1/Apaf-1 family \\
\hline $16 \mathrm{q} 23$ & ADAMTS18 & AR & 267750 & Knobloch syndrome & $\begin{array}{l}\text { a member of the ADAMTS (a disintegrin and } \\
\text { metalloproteinase with thrombospondin motifs) protein } \\
\text { family }\end{array}$ \\
\hline $16 \mathrm{q} 22 \mathrm{q} 23$ & $M A F$ & $\mathrm{AD}$ & 601088 & Aymé-Gripp syndrome & $\begin{array}{l}\text { a DNA-binding, leucine zipper-containing transcription } \\
\text { factor }\end{array}$ \\
\hline $17 \mathrm{p} 13.3$ & YWHAE & $\mathrm{AD}$ & 247200 & Miller-Dieker lissencephaly syndrome & $\begin{array}{l}\text { member of the 14-3-3 family of proteins which mediate } \\
\text { signal transduction by binding to phosphoserine-containing } \\
\text { proteins }\end{array}$ \\
\hline $17 q 12$ & PEX12 & AR & 614859 & Zellweger syndrome & member of the peroxin- 12 family \\
\hline $17 \mathrm{q} 21$ & WNT3 & AR & 273395 & tetraamelia syndrome & secreted signaling proteins implicated in oncogenesis \\
\hline $17 \mathrm{q} 21.33$ & XYLT2 & AR & 605822 & spondyloocular syndrome & $\begin{array}{l}\text { an isoform of xylosyltransferase, which belongs to a family } \\
\text { of glycosyltransferases }\end{array}$ \\
\hline $18 \mathrm{q} 12.3$ & EPG5 & $\mathrm{AR}$ & 242840 & $\begin{array}{l}\text { Vici syndrome (immunodeficiency, cleft lip/palate, } \\
\text { cataract, hypopigmentation, absent corpus callosum) }\end{array}$ & $\begin{array}{l}\text { a large coiled-coil domain-containing protein that functions } \\
\text { in autophagy }\end{array}$ \\
\hline $18 \mathrm{q} 23$ & CTDP1 & $\mathrm{AR}$ & 604168 & congenital cataracts, facial dysmorphism, neuropathy & $\begin{array}{l}\text { a protein which interacts with the carboxy-terminus of the } \\
\text { RAP74 subunit of transcription initiation factor TFIIF }\end{array}$ \\
\hline $19 q 13.1$ & $M A N 2 B 1$ & AR & 248500 & alpha-mannosidosis & $\begin{array}{l}\text { an enzyme that hydrolyzes terminal, nonreducing } \\
\text { alpha-D-mannose residues in alpha-D-mannosides }\end{array}$ \\
\hline $19 q 13.3$ & $D M P K$ & $\mathrm{AD}$ & 160900 & myotonic dystrophy 1 & a serine-threonine kinase \\
\hline $19 q 13.32$ & $F K R P$ & AR & 613153 & muscular dystrophy-dystroglycanopathy & $\begin{array}{l}\text { a protein which is targeted to the medial Golgi apparatus } \\
\text { and is necessary for posttranslational modification of } \\
\text { dystroglycan }\end{array}$ \\
\hline $20 \mathrm{p} 11.21 \mathrm{q} 12$ & $A B H D 12$ & AR & 612674 & $\begin{array}{l}\text { polyneuropathy, hearing loss, ataxia, retinitis } \\
\text { pigmentosa, cataract }\end{array}$ & $\begin{array}{l}\text { an enzyme that catalyzes the hydrolysis of } 2 \text {-arachidonoyl } \\
\text { glycerol }\end{array}$ \\
\hline $20 \mathrm{q} 13.13 \mathrm{q} 13.2$ & SALL4 & $\mathrm{AD}$ & 607323 & Duane-radial ray syndrome & $\begin{array}{l}\text { a zinc finger transcription factor thought to play a role in the } \\
\text { development of abducens motor neurons }\end{array}$ \\
\hline $20 \mathrm{q} 13.3$ & GNAS & $\mathrm{AD}$ & $\begin{array}{l}103580 / \\
612462 / \\
612463\end{array}$ & $\begin{array}{l}\text { pseudohypoparathyroidism type } 1 \mathrm{~A} / \\
\text { pseudohypoparathyroidism type } 1 \mathrm{C} / \\
\text { pseudohypoparathyroidism }\end{array}$ & multiple transcript variants encoding different isoforms \\
\hline $21 \mathrm{q} 22.3$ & COL18A1 & $\mathrm{AR}$ & 267750 & Knobloch syndrome 1 & alpha chain of type XVIII collagen \\
\hline $22 q 11.21$ & PEX26 & AR & 614872 & Zellweger syndrome & member of the peroxin-26 gene family \\
\hline $22 \mathrm{q} 12.2$ & NF2 & $\mathrm{AD}$ & 101000 & neurofibromatosis type 2 & a protein similar to ezrin, radixin, moesin family of proteins \\
\hline $22 \mathrm{q} 12.3$ & $L A R G E$ & AR & 613154 & muscular dystrophy-dystroglycanopathy & a member of the $\mathrm{N}$-acetylglucosaminyltransferase gene family \\
\hline $22 \mathrm{q} 13.1$ & MYH9 & $\mathrm{AD}$ & 153640 & Fechtner syndrome & a conventional non-muscle myosin \\
\hline
\end{tabular}


Table 1 (continued)

\begin{tabular}{|c|c|c|c|c|c|}
\hline Locus & Gene & Inheritance & OMIM & Disease & Gene product \\
\hline Xp11.4 & $B C O R$ & XL & 300166 & microphthalmia syncromic 2 & an interacting corepressor of BCL6 \\
\hline $\mathrm{Xp} 11.23$ & PQBP1 & $\mathrm{XL}$ & 309500 & Renpenning syndrome & $\begin{array}{l}\text { a nuclear polyglutamine-binding protein that is involved } \\
\text { with transcription activation }\end{array}$ \\
\hline Xp11.23p11.22 & $E B P$ & XL & 302960 & chondrodysplasia punctata 2 & an integral membrane protein of the endoplasmic reticulum \\
\hline $\mathrm{Xp} 22.3$ & ARSE & $\mathrm{XL}$ & 302950 & chondrodysplasia punctata 1 & a member of the sulfatase family \\
\hline $\mathrm{Xp} 22.3$ & HCCS & $\mathrm{XL}$ & 309801 & $\begin{array}{l}\text { linear skin defects with multiple congenital } \\
\text { anomalies }\end{array}$ & $\begin{array}{l}\text { an enzyme that covalently links a heme group to the } \\
\text { apoprotein of cytochrome c }\end{array}$ \\
\hline $\mathrm{Xp} 22$ & $A I C$ & $\mathrm{XL}$ & 304050 & Aicardi syndrome & unknown \\
\hline $\mathrm{Xp} 22.13$ & NHS & $\mathrm{XL}$ & 302350 & Nance-Horan syndrome & a protein containing 4 conserved nuclear localization signals \\
\hline $\mathrm{Xq} 22$ & GLA & $\mathrm{XL}$ & 301500 & Fabry disease & $\begin{array}{l}\text { a homodimeric glycoprotein that hydrolyzes the terminal } \\
\text { alpha-galactosyl moieties from glycolipids and glycoproteins }\end{array}$ \\
\hline $\mathrm{Xq} 22$ & COL4A5 & $\mathrm{XL}$ & 301050 & Alport syndrome & one of the 6 subunits of type IV collagen \\
\hline $\mathrm{Xq} 25 \mathrm{q} 26.1$ & OCRL & $\mathrm{XL}$ & 309000 & Lowe oculocerebrorenal syndrome & an inositol polyphosphate 5-phosphatase \\
\hline $\mathrm{Xq} 28$ & $I K B K G$ & XL & 308300 & incontinentia pigmenti & $\begin{array}{l}\text { regulatory subunit of the inhibitor of kappaB kinase } \\
\text { complex }\end{array}$ \\
\hline
\end{tabular}

$\mathrm{AD}$, autosomal dominant; $\mathrm{AR}$, autosomal recessive; $\mathrm{XL}, \mathrm{X}$ linked.

Table 2. Syndromic genes only with cataract

\begin{tabular}{|c|c|c|c|c|c|c|}
\hline Locus & Gene & OMIM & $\begin{array}{l}\text { Cataract } \\
\text { inheritance }\end{array}$ & $\begin{array}{l}\text { Syndrome } \\
\text { inheritance }\end{array}$ & Syndrome & Reference of only cataract affection \\
\hline $4 \mathrm{p} 16.1$ & WFS1 & 614296 & $\mathrm{AD}$ & $\mathrm{AD}$ & $\begin{array}{l}\text { Wolfram-like syndrome (no cataract is associated } \\
\text { with this syndrome) }\end{array}$ & Berry et al., 2013 \\
\hline $7 \mathrm{q} 34$ & $A G K$ & 212350 & $\mathrm{AR}$ & $\mathrm{AR}$ & Sengers syndrome & Aldahmesh et al., 2012 \\
\hline $8 \mathrm{q} 13.3$ & EYA1 & 601653 & $\mathrm{AD}$ & $\mathrm{AD}$ & brachio-oto-renal syndrome-1, nystagmus & Azuma et al., 2000 \\
\hline $11 \mathrm{q} 22.1 \mathrm{q} 23.2$ & $C R Y A B$ & 608810 & $\mathrm{AR} / \mathrm{AD}$ & $\mathrm{AD}$ & myofibrillar myopathy (alpha-B crystallinopathy) & $\begin{array}{l}\text { Berry et al., 2001; Liu et al., 2006; Devi et al., 2008; } \\
\text { Chen et al., 2009; Safieh et al., 2009; Sun et al., 2011b; } \\
\text { Xia et al., 2014b; Jiaox et al., 2015; Khan et al., 2015; } \\
\text { Ma AS et al., } 2016\end{array}$ \\
\hline $13 q 34$ & COL4A1 & 607595 & $\mathrm{AD}$ & $\mathrm{AD}$ & $\begin{array}{l}\text { familial porencephaly, brain small vessel disease } \\
\text { with hemorrhage/Axenfeld-Rieger anomalies, } \\
\text { hereditary angiopathy with nephropathy, } \\
\text { aneurysms, and muscle cramps }\end{array}$ & Xia et al., 2014a \\
\hline $15 q 21.1$ & FBN1 & 608328 & $\mathrm{AD}$ & $\mathrm{AD}$ & Marfan syndrome, Weill-Marchesani syndrome & Li D et al., 2016 \\
\hline $16 q 22 q 23$ & $M A F$ & 601088 & $\mathrm{AD}$ & $\mathrm{AD}$ & Aymé-Gripp syndrome & $\begin{array}{l}\text { Jamieson et al., 2002; Vanita et al., 2006; Hansen et al., } \\
\text { 2007, 2009; Narumi et al., 2014; Sun et al., 2014; Ma AS } \\
\text { et al., } 2016\end{array}$ \\
\hline $\mathrm{Xp} 22.13$ & NHS & 302350 & $\mathrm{XL}$ & $\mathrm{XL}$ & Nance-Horan syndrome & $\begin{array}{l}\text { Ramprasad et al., 2005; Florijn et al., 2006; Sharma et } \\
\text { al., 2008; Coccia et al., 2009; Sun et al., 2014; Li D et al., } \\
\text { 2016; Ma AS et al., } 2016\end{array}$ \\
\hline
\end{tabular}

$\mathrm{AD}$, autosomal dominant; $\mathrm{AR}$, autosomal recessive; $\mathrm{XL}, \mathrm{X}$ linked.

\section{Embryological Development of the Lens}

Briefly, from mouse studies, the lens development starts at day 22 of gestation ( $4 \mathrm{~mm}$ embryonic stage) from the surface ectoderm. Pax6 and Sox2 genes, in the optic vesicle, induce the surface ectoderm to form the lens placode, which invaginates and forms the lens vesicle [Kamachi et al., 2001; Kondoh et al., 2004]. By day 40 of gestation (10 $\mathrm{mm}$ stage), the lens vesicle is completely separated from the surface ectoderm. Group B1 SOX proteins
(SOX1, SOX2, and SOX3) activate $\gamma$-crystallin genes in the mouse lens, producing the crystallins, water-soluble proteins that comprise over $90 \%$ of the proteins of the lens [Hoehenwarter et al., 2006]. Elongating cells of the posterior end of the lens vesicle form the primary fibers, which become the embryonic nucleus in the mature lens. In the final phase of lens differentiation, several fibroblast growth factors seem to be required [McAvoy and Chamberlain, 1989; Lovicu and Overbeek, 1998]. The lens continues growing after birth, with the new secondary fibers 
Table 3. Only cataract genes

\begin{tabular}{|c|c|c|c|c|c|c|}
\hline Locus & Gene & Inheritance & Cataract phenotype & Other phenotype & Gene product & Reference \\
\hline $1 \mathrm{p} 36$ & EPHA2 & $\mathrm{AR} / \mathrm{AD}$ & $\begin{array}{l}\text { nuclear, posterior, } \\
\text { cortical, total, posterior } \\
\text { polar, subcapsular and } \\
\text { cortical, zonular }\end{array}$ & $\begin{array}{l}\text { a few reports with } \\
\text { microcornea or delay } \\
\text { development }^{\mathrm{a}, \mathrm{b}}\end{array}$ & $\begin{array}{l}\text { ephrin receptor subfamily of the } \\
\text { protein-tyrosine kinase family }\end{array}$ & $\begin{array}{l}\text { Shiels et al., 2008; Zhang et al., 2009a; Kaul et al., } \\
\text { 2010; Aldahmesh et al., 2012; Dave et al., 2013; } \\
\text { Shentu et al., 2013; Gillespie et al., 2014; Reis et } \\
\text { al., 2014; Sun et al., 2014; Bu et al., 2016; Li D et } \\
\text { al., } 2016\end{array}$ \\
\hline
\end{tabular}

\begin{tabular}{|c|c|c|c|}
\hline $2 \mathrm{q} 33 \mathrm{q} 35$ & CRYGD AD & punctate, progressive & $\begin{array}{l}\text { account for approximately } \\
\text { one-third of total lens protei }\end{array}$ \\
\hline
\end{tabular}
one-third of total lens proteins

Héon et al., 1999; Stephan et al., 1999; Kmoch et al., 2000; Santhiya et al., 2002; Nandrot et al., 2003; Burdon et al., 2004; Mackay et al., 2004; Shentu et al., 2004; Xu et al., 2004; Gu et al., 2005; Zenteno et al., 2005; Gu et al., 2006; Messina-Baas et al., 2006; Hansen et al., 2007; Plotnikova et al., 2007; Zhang et al., 2007; Devi et al., 2008; Li et al., 2008; Khan et al., 2009; Santana et al., 2009; Zhang et al., 2009b; Roshan et al., 2010; Wang et al., 2010; Sun et al., 2011b; Wang et al., 2011b; Vanita et al., 2012; Jia et al., 2013; Reis et al., 2013; Gillespie, et al., 2014; Mackay et al., 2014; Zhai et al., 2014; Zhuang et al., 2015; Gao et al., 2016; Ma AS et al., 2016; Yang et al., 2016

\begin{tabular}{|c|c|c|c|c|c|}
\hline $2 q 33 q 35$ & CRYGC & $\mathrm{AD}$ & $\begin{array}{l}\text { central zonular } \\
\text { pulverulent } \\
\text { (Coppock-like) }\end{array}$ & $\begin{array}{l}\text { some cases with } \\
\text { microphthalmia and } \\
\text { microcornea }\end{array}$ & $\begin{array}{l}\text { constitute the major proteins of } \\
\text { vertebrate eye lens }\end{array}$ \\
\hline
\end{tabular}

Héon et al., 1999; Ren et al., 2000; Santhiya et al., 2002; Gonzalez-Huerta et al., 2007; Devi et al., 2008; Yao et al., 2008; Zhang et al., 2009b; Kumar et al., 2011; Guo et al., 2012; Li et al. 2012; Kondo et al., 2013; Reis et al., 2013; Gillespie et al., 2014; Prokudin et al., 2014; Li D et al., 2016; Ma AS et al., 2016

\begin{tabular}{|c|c|c|c|c|c|}
\hline $2 q 33 q 35$ & CRYGB & $\mathrm{AD}$ & $\begin{array}{l}\text { anterior polar and } \\
\text { lamellar }\end{array}$ & $\begin{array}{l}\text { account for approximately } \\
\text { one-third of total lens proteins }\end{array}$ & AlFadhli et al., 2012 \\
\hline $2 q 33 q 35$ & CRYGA & sporadic & total & $\begin{array}{l}\text { major protein components of the } \\
\text { vertebrate eye lens }\end{array}$ & Li D et al., 2016 \\
\hline $3 \mathrm{p} 21.31$ & FYCO1 & $\mathrm{AR}$ & $\begin{array}{l}\text { posterior capsular, } \\
\text { nuclea }\end{array}$ & $\begin{array}{l}\text { plays a role in microtubule plus } \\
\text { end-directed transport of } \\
\text { autophagic vesicles }\end{array}$ & $\begin{array}{l}\text { Chen et al., 2011; Aldahemesh et al., 2012; } \\
\text { Gillespie et al., 2014; Khan et al., } 2015\end{array}$ \\
\hline $3 q 21 q 22$ & BFSP2 & $\mathrm{AD} / \mathrm{AR}$ & $\begin{array}{l}\text { nuclear, pulverulent, } \\
\text { cortical, Y-sutural, } \\
\text { lamellar, opalescent, } \\
\text { spok-like opacities, } \\
\text { sutural }\end{array}$ & $\begin{array}{l}\text { conforms the cytoskeletal element } \\
\text { referred to as the beaded filament }\end{array}$ & $\begin{array}{l}\text { Conley et al., 2000; Jakobs et al., 2000; Zhang et } \\
\text { al., 2004; Zhang et al., 2006; Cui et al., 2007; } \\
\text { Ma et al., 2008; Aldahmesh et al., 2011, 2012; } \\
\text { Gillespie et al., 2014; Liu et al., 2014; Li D et al., } \\
2016\end{array}$ \\
\hline $3 q 25 q t e r$ & CRYGS & $\mathrm{AD}$ & $\begin{array}{l}\text { central pulverulent, } \\
\text { opalescent, sutural, } \\
\text { lamellar, Coppock }\end{array}$ & $\begin{array}{l}\text { is expressed late abundantly in the } \\
\text { ocular lens }\end{array}$ & $\begin{array}{l}\text { Sun et al., 2005; Devi et al., 2008; Vanita et al., } \\
\text { 2009; Sun et al., 2011a; Yang et al., } 2013\end{array}$ \\
\hline $5 q 22$ & WDR36 & sporadic & posterior polar, nuclear & $\begin{array}{l}\text { a member of the WD repeat } \\
\text { protein family }\end{array}$ & Li D et al. 2016 \\
\hline $6 \mathrm{p} 24.2$ & GCNT2 & AR & central, nuclear, polar $\quad$ adult i blood group & $\begin{array}{l}\text { enzyme responsible for formation } \\
\text { of the blood group I antigen }\end{array}$ & $\begin{array}{l}\text { Yu et al., 2001; Inaba et al., 2003; Pras et al., } \\
\text { 2004; Wussuki-Lior et al., 2011; Aldahmesh et } \\
\text { al., 2012; Borck et al., 2012; Happ et al., } 2016\end{array}$ \\
\hline $6 \mathrm{p} 21.31$ & LEMD2 & $\mathrm{AR}$ & Hutterite type & $\begin{array}{l}\text { a transmembrane protein of the } \\
\text { inner nuclear membrane that is } \\
\text { involved in nuclear structure } \\
\text { organization }\end{array}$ & Boone et al., 2015 \\
\hline $9 \mathrm{p} 22.1$ & RRAGA & $\mathrm{AD}$ & nuclear & a Ras-related GTP-binding A & Chen et al., 2016 \\
\hline $9 q 13 q 22$ & CTPL1 & $\mathrm{AR}$ & progressive pulverulent & unknown & Héon et al., 2001; Forshew et al., 2005 \\
\hline $9 q 22.33$ & TDRD7 & $\mathrm{AR}$ & polar & $\begin{array}{l}\text { a member of the Tudor family of } \\
\text { proteins }\end{array}$ & Lachke et al., 2011; Li D et al., 2016 \\
\hline $10 \mathrm{p} 13$ & $V I M$ & $\mathrm{AD}$ & pulverulent & $\begin{array}{l}\text { a member of the intermediate } \\
\text { filament family }\end{array}$ & Müller et al., 2009; Ma AS et al., 2016 \\
\hline
\end{tabular}


Table 3 (continued)

\begin{tabular}{|c|c|c|c|c|c|c|}
\hline Locus & Gene & Inheritance & Cataract phenotype & Other phenotype & Gene product & Reference \\
\hline $12 \mathrm{q} 13$ & MIP & $\mathrm{AD}$ & $\begin{array}{l}\text { lamellar, sutural, } \\
\text { cerulean, punctate, } \\
\text { nuclear, pulverulent, } \\
\text { snail-like, cortical, } \\
\text { Y-sutural }\end{array}$ & & $\begin{array}{l}\text { a member of the } \\
\text { water-transporting aquaporins as } \\
\text { well as the original member of the } \\
\text { MIP family of channel proteins }\end{array}$ & $\begin{array}{l}\text { Berry et al., 2000; Geyer et al., 2006; Gu et al., } \\
\text { 2007; Lin et al., 2007; Jiang et al., 2009; Wang et } \\
\text { al., 2010; Wang et al. 2011a; Xiao et al., 2011; } \\
\text { Yang et al., 2011b; Reis et al., 2013; Senthil } \\
\text { Kumar et al., 2013; Zeng et al., 2013; Ding et al., } \\
\text { 2014; Sun et al., 2014; Yu et al., 2014; Shentu et } \\
\text { al., 2015; Song et al., 2015; Ma AS et al., 2016; } \\
\text { Qin et al., } 2016\end{array}$ \\
\hline
\end{tabular}

\begin{tabular}{ll}
\hline 13q11q12 GJA3 AD $\quad$ & nuclear, pulverulent, \\
& Y-sutural, lamellar, \\
& lamerllar sutural, pearl \\
& box, coralliform,
\end{tabular}

gap junction protein alpha 3

Mackay et al., 1999; Rees et al., 2000; Jiang et al., 2003; Bennett et al., 2004; Burdon et al., 2004; Li et al., 2004; Devi et al., 2005; Ma et al., 2005;

Addison et al., 2006; Hansen et al., 2006, 2009;

punctate, Coppock-like

Guleria et al., 2007; Santhiya et al., 2010; Zhou Z

et al., 2010; Bennett and Shiels, 2011; Ding et al.,

2011; Sun et al., 2011a; Yang et al., 2011a; Yao et al., 2011b; Wang and Zhu, 2012; Zhang et al.,

2012; Guo et al., 2013; Ponnam et al., 2013;

Zhou et al., 2013; Gillespie et al., 2014; Hu et al.,

2014; Yang Z et al., 2015; Yuan et al., 2015; Li B

et al., 2016; Ma AS et al., 2016; Ma MF et al.,

2016; Wang et al., 2016

\begin{tabular}{|c|c|c|c|c|}
\hline $16 \mathrm{p} 13.2$ & TMEM114 AD & & $\begin{array}{l}\text { a glycosylated transmembrane } \\
\text { protein }\end{array}$ & Jamieson et al., 2007 \\
\hline $16 \mathrm{q} 21$ & $\mathrm{AD} / \mathrm{AR}$ & $\begin{array}{l}\text { cortical lamellar, } \\
\text { zonular, anterior polar, } \\
\text { nuclear, sutural }\end{array}$ & heat-shock transcription factor & $\begin{array}{l}\text { Bu et al., 2002; Smaoui et al., 2004; Forshew et } \\
\text { al., 2005; Ke et al., 2006; Sajjad et al., 2008; } \\
\text { Hansen et al., 2009; Gillespie et al., 2014; Lv et } \\
\text { al., 2014; Liu et al., 2015; Behnam et al., 2016; } \\
\text { Li D et al., } 2016\end{array}$ \\
\hline
\end{tabular}

\begin{tabular}{|c|c|c|c|c|c|c|}
\hline $17 q 11.2 q 12$ & CRYBA1 & $\mathrm{AD} / \mathrm{AR}$ & $\begin{array}{l}\text { zonular sutural, } \\
\text { pulverulent, sutural } \\
\text { nuclear, lamellar, } \\
\text { floriform, Y-sutural, } \\
\text { nuclear, polymorphic }\end{array}$ & & crystallin structure proteins & $\begin{array}{l}\text { Kannabiran et al., 1998; Bateman et al., 2000; } \\
\text { Burdon et al., 2004; Ferrini et al., 2004; Reddy et } \\
\text { al., 2004; Qi et al., 2004; Lu et al., 2007; Devi et } \\
\text { al., 2008; Gu et al., 2010; Zhu et al., 2010; Sun et } \\
\text { al., 2011b; Yang Z et al., 2011; Yang et al., 2012; } \\
\text { Yu et al., 2012; Gillespie et al., 2014; Zhang et } \\
\text { al., 2014; Khan et al., 2015 }\end{array}$ \\
\hline $17 q 12$ & UNC45B & $\mathrm{AD}$ & $\begin{array}{l}\text { posterior subcapsular } \\
\text { and central }\end{array}$ & & $\begin{array}{l}\text { a co-chaperone required for } \\
\text { folding and accumulation of type } \\
\text { II myosins }\end{array}$ & Hansen et al., 2014 \\
\hline $17 \mathrm{q} 24$ & GALK1 & $\mathrm{AR}$ & & $\begin{array}{l}\text { galactokinase } \\
\text { deficiency }\end{array}$ & galactokinase 1 & $\begin{array}{l}\text { Stambolian et al., 1995; Asada et al., 1999; } \\
\text { Kalaydjieva et al., 1999; Kolosha et al., 2000; } \\
\text { Hunter et al., 2001; Reich et al., 2002; Yasmeen } \\
\text { et al., 2010; Singh et al., 2012; Chacon-Camacho } \\
\text { et al., 2014; Gillespie et al., 2014 }\end{array}$ \\
\hline $19 \mathrm{p} 13.2$ & LONP1 & $\mathrm{AR}$ & nuclear & & $\begin{array}{l}\text { a mitochondrial matrix protein } \\
\text { that belongs to the Lon family of } \\
\text { ATP-dependent proteases }\end{array}$ & Khan et al., 2015 \\
\hline $19 q 13.13$ & WDR87 & $\mathrm{AR}$ & total white & & WD repeat domain 87 & Khan et al., 2015 \\
\hline $19 \mathrm{q} 13.2$ & $P R X$ & $\mathrm{AD}$ & nuclear & & $\begin{array}{l}\text { a protein involved in peripheral } \\
\text { nerve myelin upkeep }\end{array}$ & Yuan et al., 2016 \\
\hline $19 q 13.33$ & FTL & $\mathrm{AD}$ & $\begin{array}{l}\text { iron flecks, nuclear, } \\
\text { Y-sutural, stellate, } \\
\text { sunflower, pulverulent, } \\
\text { crystallin, } \\
\text { breadcrumb-like nuclear, } \\
\text { cortical opacities }\end{array}$ & hyperferritinemia & $\begin{array}{l}\text { the light subunit of the ferritin } \\
\text { protein }\end{array}$ & $\begin{array}{l}\text { http://www.hgmd.cf.ac.uk/ac/gene. } \\
\text { php?gene=FTL }\end{array}$ \\
\hline $19 \mathrm{q} 13.4$ & LIM2 & $\mathrm{AR}$ & congenital & $\begin{array}{l}\text { galactokinase } \\
\text { deficiency }\end{array}$ & $\begin{array}{l}\text { an eye lens-specific protein found } \\
\text { at the junctions of lens fiber cells }\end{array}$ & Ponnam et al., 2008 \\
\hline $19 q 33$ & SIPA1L3 & $\mathrm{AR}$ & & & $\begin{array}{l}\text { the signal-induced proliferation } \\
\text { associated } 1 \text { family of genes }\end{array}$ & Greenlees et al., 2015 \\
\hline $20 \mathrm{p} 11.23 \mathrm{p} 12.1$ & BFSP1 & $\mathrm{AR}$ & $\begin{array}{l}\text { cortical progressive, } \\
\text { juvenile onset, nuclear }\end{array}$ & & $\begin{array}{l}\text { a lens-specific intermediate } \\
\text { filament-like protein named } \\
\text { filensin }\end{array}$ & $\begin{array}{l}\text { Ramachandran et al., 2007; Wang et al., 2013; } \\
\text { Li D et al., 2016; Ma AS et al., } 2016\end{array}$ \\
\hline $20 q 11.22$ & CHMP $4 B$ & $\mathrm{AD}$ & posterior subcapsular & & $\begin{array}{l}\text { a member of the chromatin- } \\
\text { modifying protein/charged } \\
\text { multivesicular body protein family }\end{array}$ & Shiels et al., 2007 \\
\hline
\end{tabular}


Table 3 (continued)

\begin{tabular}{|c|c|c|c|c|c|c|}
\hline Locus & Gene & Inheritance & Cataract phenotype & Other phenotype & Gene product & Reference \\
\hline $21 \mathrm{q} 22.3$ & LSS & $\mathrm{AR}$ & total & ? & $\begin{array}{l}\text { catalyzes the conversion of } \\
\text { (S)-2,3-oxidosqualene to lanosterol }\end{array}$ & Zhao et al., 2015 \\
\hline $22 \mathrm{q} 11.23$ & $C R Y B B 3$ & $\mathrm{AR} / \mathrm{AD}$ & nuclear, cortical & & crystallin protein & $\begin{array}{l}\text { Riazuddin et al., 2005; Hansen et al., 2009; Reis } \\
\text { et al., 2013; Li D et al., 2016; Ma AS et al., } 2016\end{array}$ \\
\hline $22 \mathrm{q} 11.23$ & $C R Y B B 2$ & $\mathrm{AD}$ & $\begin{array}{l}\text { subcapsular, zonular, } \\
\text { nuclear, coronary, } \\
\text { lamellar, sutural, } \\
\text { cerulean, pulverulent, } \\
\text { polymorphic, cortical }\end{array}$ & & crystallin protein & $\begin{array}{l}\text { Litt et al., 1997; Gill et al., 2000; Vanita et al., } \\
\text { 2001; Santhiya et al., 2004; Yao et al., 2005; } \\
\text { Bateman et al., 2007; Pauli et al., 2007; Devi et } \\
\text { al., 2008; Li et al., 2008; Hansen et al., 2009; Lou } \\
\text { et al., 2009; Mothobi et al., 2009; Wang et al., } \\
\text { 2009; Santhiya et al., 2010; Wang et al., 2011b; } \\
\text { Yao et al., 2011a; Weisschuh et al., 2012; Chen et } \\
\text { al., 2013; Faletra et al., 2013; Garnai et al., 2014; } \\
\text { Gillespie et al., 2014; Sun et al., 2014; Ma AS et } \\
\text { al., 2016; Messina-Baas et al., } 2016\end{array}$ \\
\hline $22 \mathrm{q} 12.1$ & $C R Y B B 1$ & $\mathrm{AR} / \mathrm{AD}$ & nuclear & & crystallin protein & $\begin{array}{l}\text { Willoughby et al., 2005; Cohen et al., 2007; } \\
\text { Wang et al., 2007; Yang et al., 2008; Meyer et al., } \\
\text { 2009; Wang et al., 2011b; Khan et al., 2012; Reis } \\
\text { et al., 2013; Wu et al., 2013; Ma AS et al., } 2016\end{array}$ \\
\hline
\end{tabular}

For abbreviations, see Table 2. ${ }^{\text {a }}$ Gillespie et al., 2014. ${ }^{\mathrm{b}}$ Aldahmesh et al., 2012.

generated from the equatorial cells of the lens epithelium (germinative zone). The lens epithelial cells synthesize crystallins and lose their nuclei to become mature lens fibers. Disruption of this delicate process due to toxic, metabolic, infectious, or genetic agents results in CC.

\section{Syndromic and Nonsyndromic Cataracts}

A rough division of hereditary cataracts comprises 2 parts: syndromic and nonsyndromic cataracts. If only the lens is implicated in the pathological process, it is defined as nonsyndromic cataracts. If there are more organs implicated, it results in syndromic cataracts. Around 100 genes throughout the genome are in the OMIM database explaining the different syndromes caused by different genes, either associated with cataracts or as part of them (Table 1). Nevertheless, genetically it is sometimes difficult to establish this difference because clinically one gene defect can result in either lens affection or systemic disease. Some examples of this variance (Table 2) are found in the affected $A G K$ gene, which results in either an isolated cataract or in Senger syndrome (OMIM 212350) [Aldahmesh et al., 2012]; the MAF gene, in which a molecular defect can result in cataracts or in Aymé-Gripp syndrome (OMIM 601088) [Narumi et al., 2014; Sun et al., 2014; Ma AS et al., 2016], or in the NHS gene alteration which can lead to isolated cataracts or Nance-Horan syndrome (OMIM 302350) [Coccia et al., 2009; Li D et al., 2016]. The scope of this review does not include syn- dromic cataracts. It is only briefly referenced because some genes (WFS1, AGK, EYA1, CRYAB, COL4A1, FBN1, $M A F$, and $N H S)$ are also described in previous reports with CC and no other anomalies (Table 2).

\section{Nonsyndromic Cataracts}

Around 35 genes have been strongly associated with inherited CC only and with no other systemic anomalies; they show autosomal dominant and autosomal recessive inheritance patterns (Table 3). However, in some of these cases (EPHA2, BFSP2, HSF4, CRYBA1, CRYBB1, and $C R Y B B 3$ ), hereditary $C C$ can present both patterns of autosomal inheritance (dominant or recessive). A great variety of functions is described in all affected genes that produce nonsyndromic inherited CC. Protein functions encompass structural to enzymatic processes including channels, phagosomes, RNA processing, transcription factors, and regulation of intracellular signaling (Table 3 ).

The cataract phenotype by itself is not an efficient indicator of the affected gene or mutation, since identical cataracts can result from mutations at different loci and may have several inheritance patterns. Conversely, various cataract types can be found in the same gene affection, presenting clinical heterogeneity. In addition, some nonsyndromic cataracts could include the presence of lens opacities only or lens opacities with ocular abnormalities and with no systemic affection, i.e., microcornea, aniridia, vitreoretinochoroidopathy, microphthalmia, anophthalmia, iris hypoplasia, or rod-cone dystrophy (Table 4). 
Table 4. Cataract genes and eye anomalies

\begin{tabular}{llll}
\hline Locus & Gene & Inheritance & Cataract phenotyp \\
\hline $1 \mathrm{p} 32$ & FOXE3 & AR/AD & cerulean, congenital
\end{tabular}

yital

Other phenotype

microphthalmia,

sclerocornea, aphakia, optic

disc coloboma, aniridia plus,

glaucoma, viteoretinal

dysplasia (almost all reports)

Gene product

Reference

the forkhead family of

transcription factors

Semina et al., 2001; Ormestad et al., 2002;

Valleix et al., 2006; Iseri et al., 2009; Ali et

al., 2010; Anjum et al., 2010; Bremond-

Gignac et al., 2010; Reis et al., 2010;

Doucette et al., 2011; Gillespie et al., 2014;

Li D et al., 2016

\begin{tabular}{ll}
\hline 1q21.1 GJA8 $\quad$ AD/AR & nuclear, punctiform, \\
& pulverulent, jellyfish-like, \\
& star-shaped, full moon, \\
& Y-sutural, balloon-like, \\
& lamelar, zonular, nuclear, \\
& triangular, perinuclear
\end{tabular}

microcornea, glaucoma

(about half of the reports)

a transmembrane connexin

Shiels et al., 1998; Berry et al., 1999;

Polyakov et al., 2001; Willoughby et al.,

2003; Zheng et al., 2005; Arora et al., 2006,

2008; Devi and Vijayalakshmi, 2006; Vanita et al., 2006; Hansen et al., 2007; Ponnam et al., 2007; Lin et al., 2008; Schmidt et al.,

2008; Vanita et al., 2008; Yan et al., 2008;

Graw et al., 2009; Hansen et al., 2009;

Wang et al., 2009; Gao et al., 2010; Hu et

al., 2010; He et al., 2011; Kumar at al., 2011;

Sun et al., 2011a; Wang L et al., 2011; Li et

al., 2013; Ponnam et al., 2013; Reis et al.,

2013; Su et al., 2013; Chen et al., 2014; Ge

et al., 2014; Gillespie et al., 2014; Mackay et

al., 2014; Prokudin et al., 2014; Sun et al.,

2014; Zhu et al., 2014; Chen et al., 2015;

Liang et al., 2015; Yang Z et al., 2015; Ma

AS et al., 2016; Min et al., 2016; Yu et al., 2016

\begin{tabular}{llll}
\hline 9q21.12 & TRPM3 & AD & open-angle glaucoma \\
\hline $11 \mathrm{p} 13$ & PAX6 & AD & \\
& & $\begin{array}{l}\text { aniridia "plus" (iris and } \\
\text { foveal hypoplasia, } \\
\text { nystagmus, cataract, corneal } \\
\text { abnormalities, glaucoma) }\end{array}$ \\
\hline
\end{tabular}

\begin{tabular}{lll}
\hline $11 \mathrm{q} 13 \quad$ BEST1 & pD $\quad \begin{array}{l}\text { vitreoretinochoroidopathy, } \\
\text { microcornea, rod-cone } \\
\text { dystrophy, cataract, posterior } \\
\text { staphyloma }\end{array}$ \\
\hline
\end{tabular}

\begin{tabular}{lll}
\hline $14 \mathrm{q} 24.3 \quad$ VSX2 & AR & $\begin{array}{l}\text { microphthalmia, } \\
\text { anophthalmia, iris coloboma }\end{array}$
\end{tabular}

\begin{tabular}{lllll}
\hline $15 \mathrm{q} 22.32$ & NR2E3 & AD, AR & & $\begin{array}{l}\text { retinitis pigmentosa-37, } \\
\text { enhanced S-cone syndrome }\end{array}$ \\
\hline $15 \mathrm{q} 25.1$ & MIR184 & AD & $\begin{array}{l}\text { congenital, early-onset } \\
\text { anterior polar }\end{array}$ & $\begin{array}{l}\text { endothelial dystrophy, iris } \\
\text { hypoplasia, cataract and } \\
\text { stromal thining (EDICT) } \\
\end{array}$ \\
& & $\begin{array}{l}\text { syndrome, keratoconus. } \\
\text { Corneal anomalies }\end{array}$
\end{tabular}

\begin{tabular}{llll}
\hline 17p13.1 & GUCY2D & AR & \\
\hline 21q22.3 & CRYAA & AR/AD & nuclear, laminar, posterior \\
& & polar, punctate, spike-like, \\
& ring-like, fan-shaped, \\
& disc-like, Y-sutural, \\
& & zonular, lamellar, \\
& & polymorphic, perinuclear
\end{tabular}

\begin{tabular}{lll}
$\begin{array}{l}\text { Leber congenital } \\
\text { amaurosis-1 }\end{array}$ & $\begin{array}{l}\text { a retina-specific guanylate } \\
\text { cyclase }\end{array}$ & Gradstein et al., 2016 \\
$\begin{array}{l}\text { microcornea, iris coloboma, } \\
\begin{array}{l}\text { axial elongation, macular } \\
\text { hypoplasia, corneal opacity }\end{array}\end{array}$ & $\begin{array}{l}\text { chaperone-like small heat- } \\
\text { shock protein family }\end{array}$ & $\begin{array}{l}\text { Litt et al., 1998; Pras et al., 2000; Mackay et } \\
\text { al., 2003; Graw et al., 2006; Santhiya et al., } \\
\text { 2006; Vanita et al., 2006; Beby et al., 2007; } \\
\text { Hansen et al., 2007; Khan et al., 2007; Devi } \\
\text { et al., 2008; Gu et al., 2008; Richter et al., } \\
\text { 2008; Hansen et al., 2009; Santana et al., }\end{array}$ \\
& $\begin{array}{l}\text { 2009; Zhang et al., 2009a; Li et al., 2010; } \\
\text { Sun et al., 2011a; Su et al., 2012; Wang and }\end{array}$ \\
& $\begin{array}{l}\text { Zhu, 2012; Kondo et al., 2013; Laurie et al., } \\
\text { 2013; Reis et al., 2013; Yang et al., 2013; }\end{array}$ \\
& Kong et al., 2015; Liang et al., 2015; \\
& Javadiyan et al., 2016; Li D et al., 2016; \\
& Ma AS et al., 2016 \\
\hline microcornea, & Billingsley et al., 2006; Zhou G et al., 2010 \\
microphthalmia & \\
\hline & soluble proteins in the human \\
\hline
\end{tabular}

\begin{tabular}{lllll}
\hline 22q12.1 CRYBA4 & AD & congenital nuclear, lamellar & $\begin{array}{l}\text { microcornea, } \\
\text { microphthalmia }\end{array}$ & \multicolumn{1}{c}{$\begin{array}{l}\text { soluble proteins in the human } \\
\text { lens }\end{array}$} \\
\hline
\end{tabular}

For abbreviations, see Table 2.

family of transient receptor Bennett et al., 2014

potential channels

a homeobox and paired

LOVD PAX6 Homepage

that binds DNA

a member of the bestrophin Boon et al., 2009

gene family

a homeobox protein originally Ferda Percin et al., 2000

described as a retina-specific transcription factor

a family of nuclear receptor $\quad$ Edwards et al., 2008

transcription factors

microRNAs involved in posttranscriptional regulation of

gene expression

Iliff et al., 2012; Bykhovskaya et al., 2015

a retina-specific guanylate
cyclase

.


Fig. 2. The structure of CRYGD, from https://swissmodel.expasy.org/.
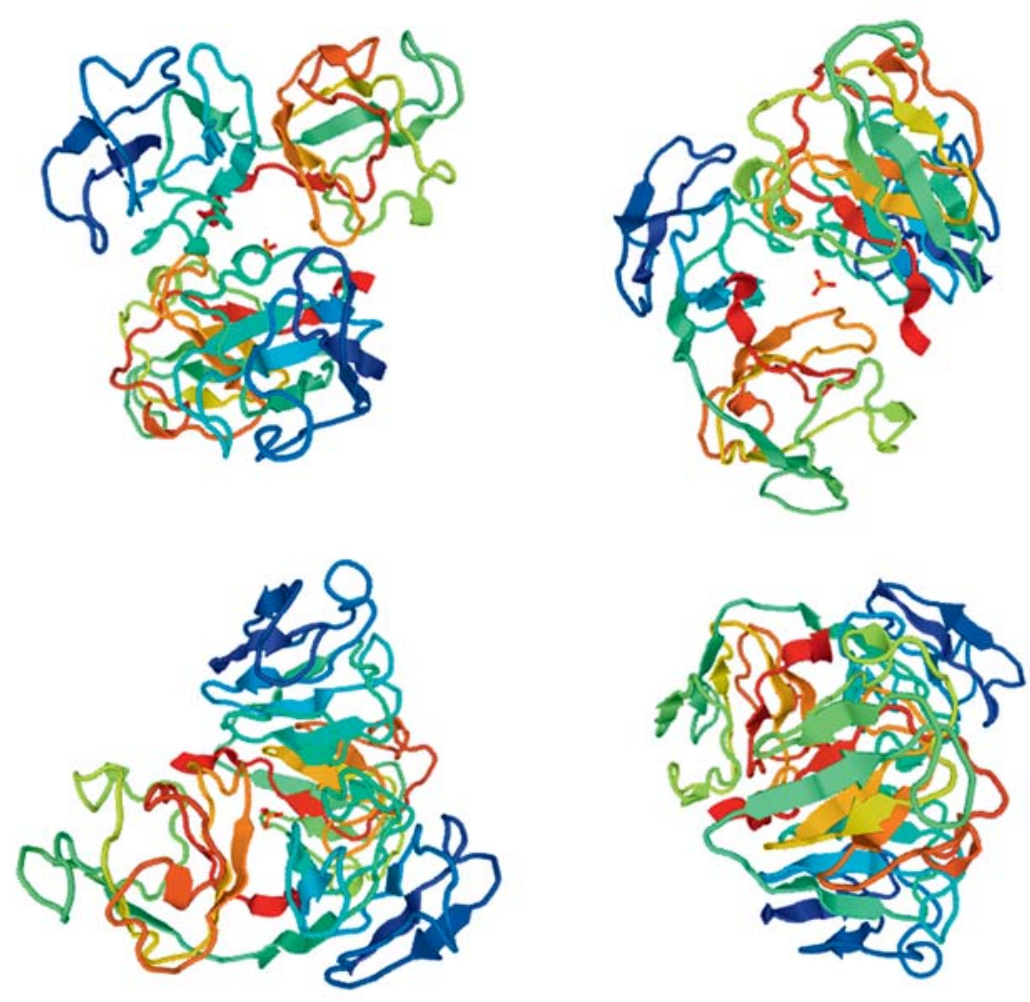

Crystallins

Crystallins are divided in $\alpha, \beta$, and $\gamma$ and constitute around $90 \%$ of the soluble proteins of the lens with an asymmetric and biphasic distribution [Augusteyn, 2010]. $\alpha$-crystallins ( $\alpha \mathrm{A}$-crystallin and $\alpha \mathrm{B}$-crystallin) belong to the chaperone-like small heat shock protein family (sHSPs). They block the formation of stress protein aggregates to avoid toxic effects [Clark et al., 2012]. The sHSPs are large, polydisperse, and do not crystallize, thus playing an important role in the lens. It is likely that the high refractive index of a lens with no compromise of transparency is due to the ability to form extended lattices of the water-insoluble $a$-crystallin [Slingsby et al., 2013]. Outside of the lens, $\alpha$-crystallin is expressed principally in the retina, the muscle, and the brain. In the retina, it seems to be implicated in cytoprotection, cell survival, inflammation, and autophagy [Kannan et al., 2012]. A great diversity of mutations associated with cataracts has been reported in the CRYAA and CRYAB genes, whose products are $\alpha \mathrm{A}$-crystallin and $\alpha \mathrm{B}$-crystallin, respectively. In approximately half of the cases, CRYAA gene defects are associated with eye anomalies, whereas CRYAB gene defects are associated with myofibrillar myopathy (Tables 1,4); in both cases, the rest of the reports connect lens opacities with great clinical heterogeneity (Table 4). Most cases show an autosomal dominant pattern, and in a few cases, a recessive autosomal inheritance.

The $\beta$ - and $\gamma$-crystallins consist of 4 similarly folded Greek key motifs organized into 2 domains. The Greek key motif is a structure of $4 \beta$-sheets, folded in an antiparallel form that generates a folded compact domain [Richardson, 1977]. The values and gradients in the refractive index of lens proteins seem to be related to the Greek key motif [Zhao et al., 2011]. The central portion and the embryonic nuclear region of the lens are rich in $\beta$ - and $\gamma$-crystallins. In humans, $\gamma$-crystallins comprise from $\gamma$ A to $\gamma$ F. Now, $\gamma$ S-crystallin ( $\beta S$-crystallin) is also included in this group; $\gamma \mathrm{E}$ and $\gamma \mathrm{F}$ are pseudogenes. Interestingly, CRYBA, CRYBB, CRYGA, CRYGB, CRYGC, $C R Y G D$, and $C R Y G S$ gene mutations are only associated with inherited CC and no other systemic or eye anomalies (Table 3). In Figure 2, the normal CYGD crystallin structure is shown. 
Fig. 3. The structure of EPHA2, from https://swissmodel.expasy.org/.

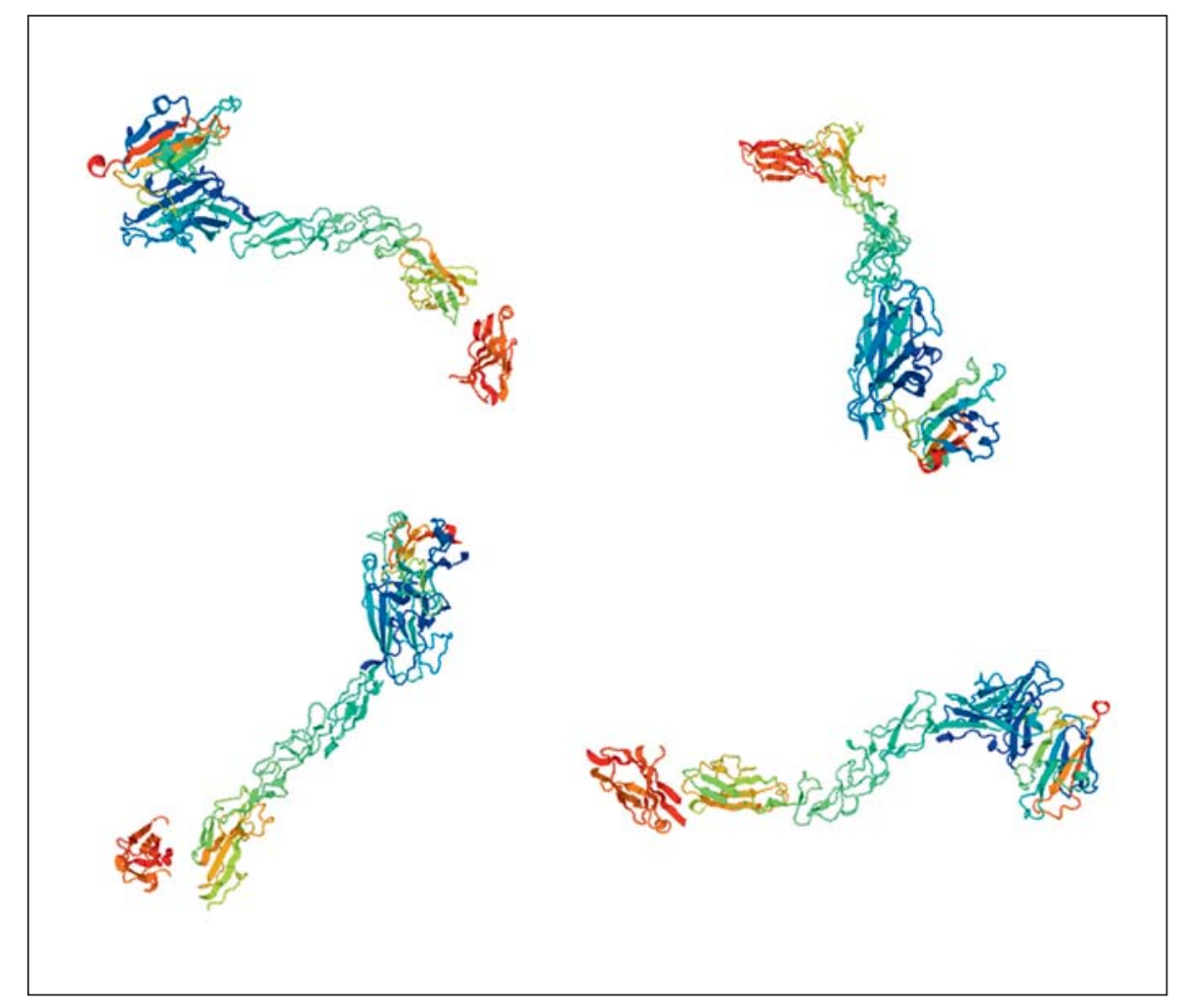

\section{EPH2}

The EPHA2 (ephrin receptor A2) gene encodes a transmembrane tyrosine kinase receptor (epithelial cell) which contains an extracellular ligand-binding domain and is expressed in the human lens [Pasquale, 2010]. EPH2, with its ligands ephrin-A1 or ephrin-A5, has a role in cell adhesion and cell repulsion [Miao and Wang, 2009]. Inhibition of EPHA2 induces apoptosis and abrogates tumorigenic growth of tumor cells [Amato et al., 2014]. Apparently, the downstream signaling of activated EPHA2 promotes the antioxidative capacity of lens epithelial cells to eradicate the overproduction of reactive oxygen species [Yang J et al., 2015]. It is probable that the loss of EPHA2 function could affect the structural stability of the cell, cell-to-cell crosstalk, protein folding and transcriptional activation [Park et al., 2013]. Thus, the cytoprotective and antiapoptotic functions of EPHA2 in the lens indicate the possible role of EPHA2 in avoiding lens opacity. Practically, all mutations reported in the EPH2 gene are associated exclusively with inherited CC and no other anomalies (some cataracts are age related, as well). Only one study reports microcornea with mild dysmorphic features [Gillespie et al., 2014]. Both autosomal recessive and domi- nant patterns as well as clinical heterogeneity are present (Table 3). Figure 3 shows the structure of the EPH2 protein.

\section{GJA3 and GJA8}

The GJA3 (gap junction alpha-3) gene encodes connexin 46, whereas the GJA8 (gap junction alpha-8) gene encodes connexin 50 , gap junction channel proteins that play an important role in lens cell homeostasis. Connexin proteins have 4 transmembrane domains, 3 intracellular regions, and 2 extracellular loops. Six connexin subunits form 1 connexon. Connexin 46 and connexin 50 are expressed in the lens fiber cells and are essential for the coupling of mature fibers in the central core of the lens [Gong et al., 1997; Martinez-Wittinghan et al., 2004]. Connexins allow the interchange of ions and low-molecular-weight molecules between contiguous cells. Connexin 46 and connexin 50 are the major components of human lens fiber cells, and their molecular defects result in about $20 \%$ of nonsyndromic cataract reports [Shiels et al., 2010]. GJA3 gene mutations produce only cataracts with no other manifestations, unlike GJA8 that includes the presence of microcornea in half of the reports (Tables 3,4). The structure of connexin 46 is shown in Figure 4. 
Fig. 4. The structure of GJA3, from https:// swissmodel.expasy.org/.

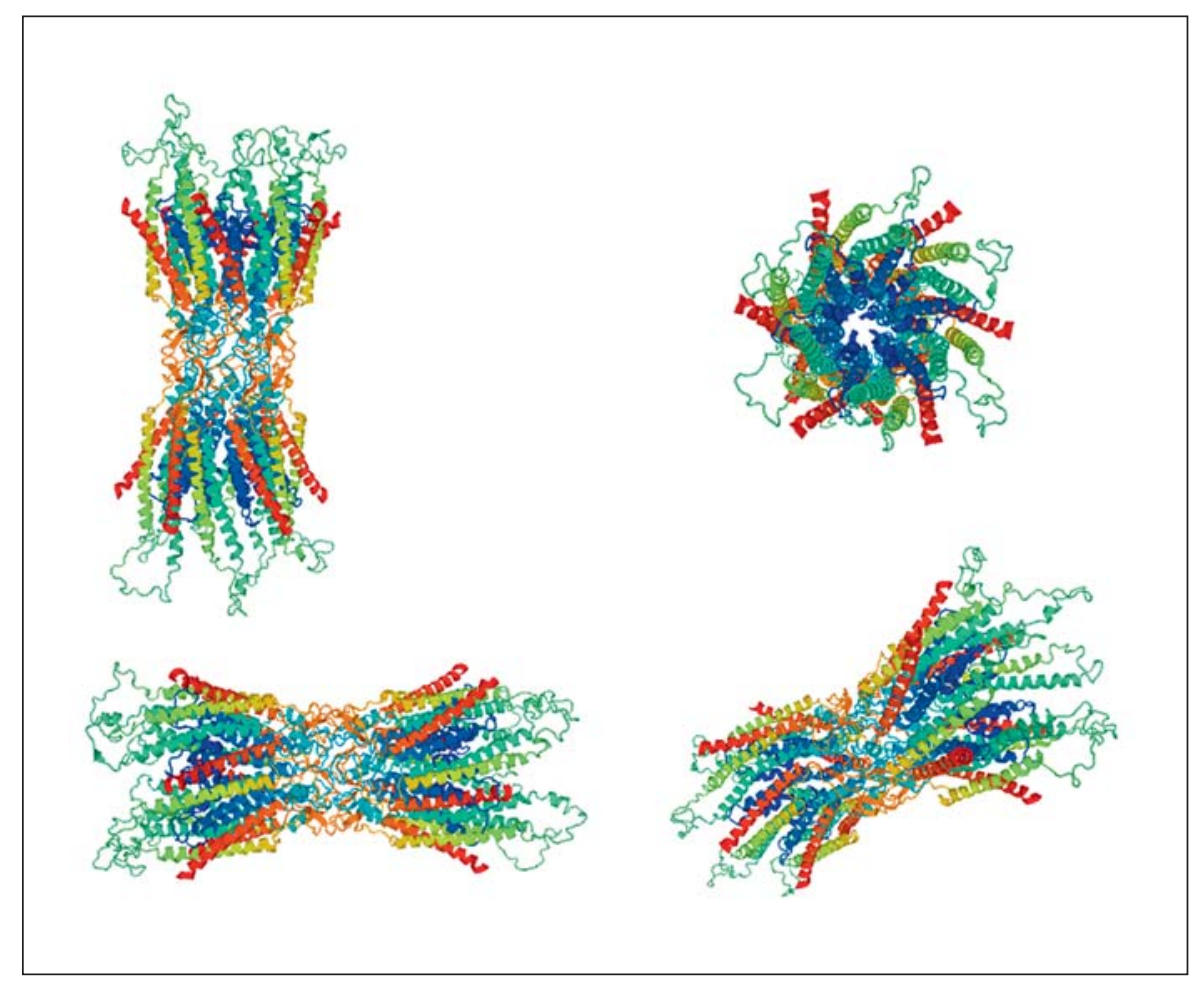

\section{MIP}

The MIP (major intrinsic protein) gene encodes aquaporin 0 (AQP0), the most abundant protein in the fiber cell membrane that functions as a water channel and belongs to the superfamily of AQPs [Shiels et al., 2001]. AQPs create a microcirculation in the avascular lens to nourish central fiber cells, maintaining their transparency and homeostasis [Gao et al., 2013]. AQP0 accounts for about $45 \%$ of the total plasma proteins [Bassnett et al., 2009]. Homozygous or heterozygous loss of AQP0 will reduce the water permeability of lens fiber cells producing lens opacities in mice [Shiels et al., 2001]. Apart from the intermolecular contacts between AQP0 monomers, AQP0 interacts with other proteins in lens fiber cells as crystallins and connexins [Liu and Liang 2008; Liu et al. 2011]. Mutations in the MIP gene result only in cataracts with no other manifestations, and all of them are inherited in an autosomal dominant pattern (Table 3). The structure of the AQP0 channel is shown in Figure 5.

\section{FYCO1}

FYCO (FYVE and coiled-coil domain containing 1), a PI(3)P-, Rab7-, and LC3-binding protein, mediates microtubule plus end-directed vesicle transport of autophagosomes, a required process for autolysosome formation
[Pankiv et al., 2010]. FYCO1 is expressed in the lens epithelium and fiber cells (principally in nuclear fibers) in newborn mice, suggesting that autophagy is important in lens fiber cell differentiation [Brennan et al., 2012]. When FYCO1 is lacking, phagosomes stay $\mathrm{p} 40 \mathrm{phox}^{+}$longer and produce more reactive oxygen. This represents FYCO1's participation in the immunity role of regulating the phagosome maturation process and production of reactive oxygen, processes necessary for handling extracellular pathogens [Ma et al., 2014]. All mutations reported in the FYCO1 gene are inherited in an autosomal recessive pattern and have no other systemic or eye anomalies (Table 3). Figure 6 shows the structure of the FYCO1 protein.

\section{BFSP1 and BFSP2}

BFSP1 (filesin, CP115) and BFSP2 (phakinin, CP49), lens-specific proteins, are the principal components of beaded filaments, which are unique cytoskeletal lens structures [Alizadeh et al., 2003]. BFSP1 and BFSP2 genes (beaded filament structural protein 1 and 2) encode these proteins. Apparently, the beaded filament is required to maintain cell morphology, 3-dimensional membrane architecture and lens transparency during fetal development and fiber cell differentiation [Alizadeh et al., 2002]. Both genes are associated with cataracts with no other 
Fig. 5. The structure of MIP, from https:// swissmodel.expasy.org/.
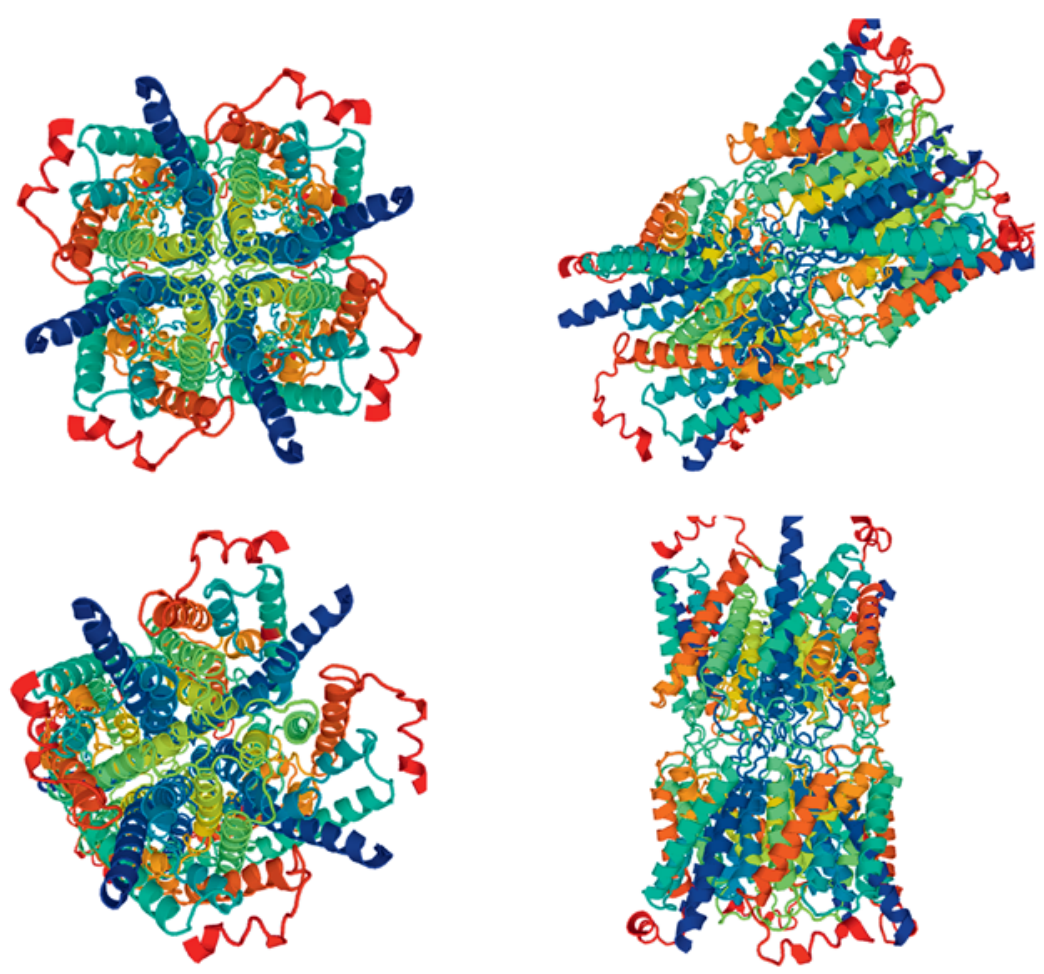

Fig. 6. The structure of FYCO1, from https://swissmodel.expasy.org/.
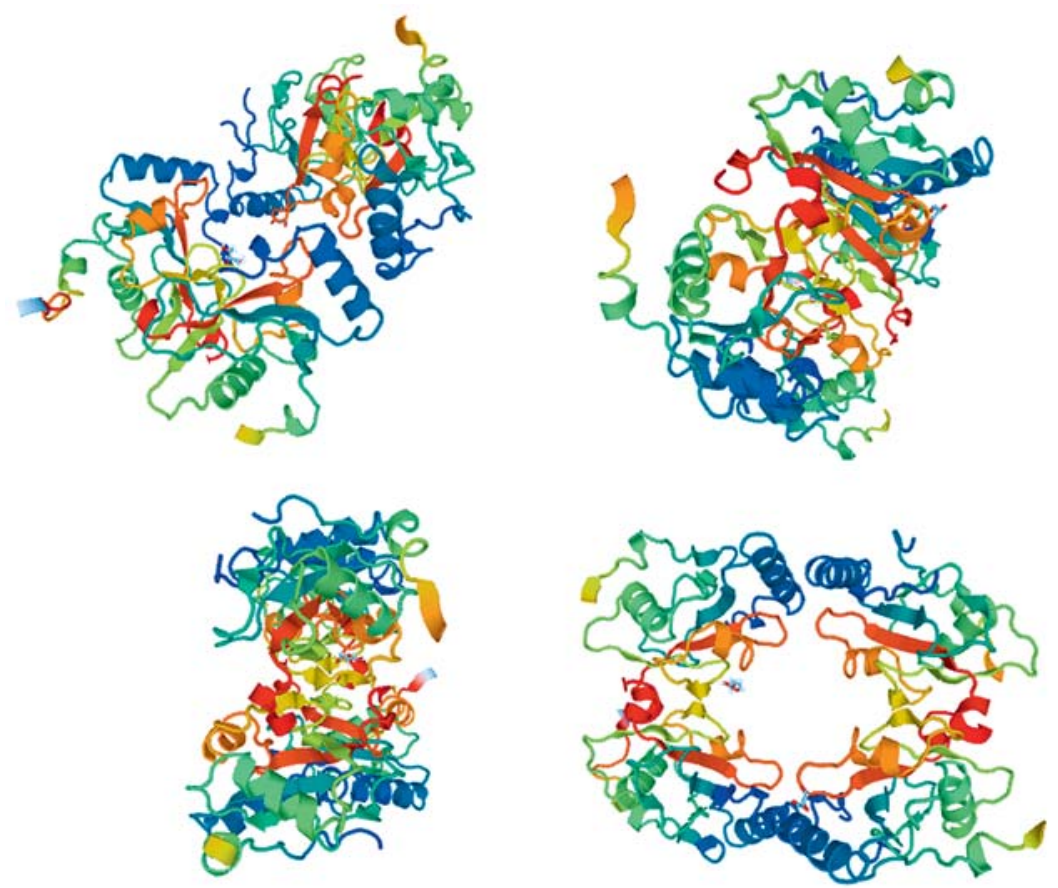


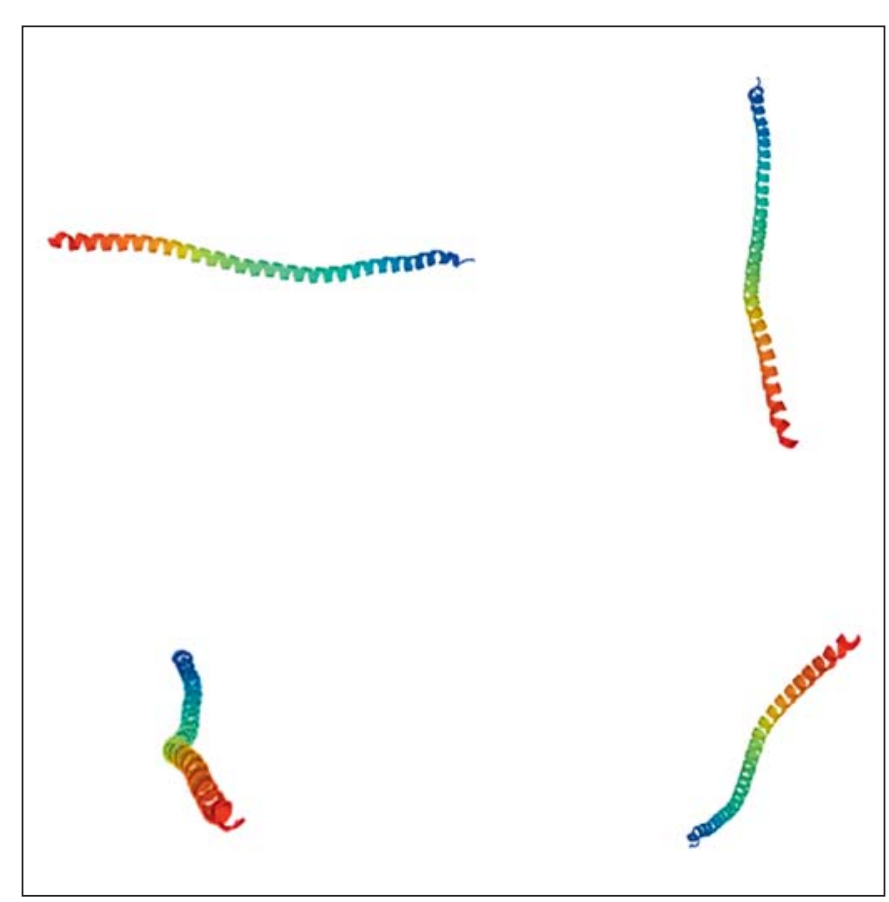

Fig. 7. The structure of BFSP1, from https://swissmodel.expasy. org/.

anomalies: the BFS1 gene inherited in an autosomal recessive pattern and the BFS2 gene inherited in autosomal dominant and recessive patterns. Figure 7 shows the BFSP1 structure.

\section{Nonsyndromic Cataracts with Eye Anomalies}

In some cases, nonsyndromic cataracts are associated with eye anomalies; about 15 genes have been reported in the literature with this condition (Tables 3,4 ), but only a few genes have consistently presented this association (BEST1, VSX2, NR2E3, MIR184, and GUCY2D). The rest of the genes (CRYGB, CRYGA, FYCO1, BFSP2, CRYGS, WDR36, GCNT2, RRAGA, CTPL1, TDRD7, VIM, MIP, GJA3, TMEM114, HSF4, CRYBA1, UNC45B, LONP1, SIPA1L3, WDR87, LIM2, BFSP1, CHMP4B, and LSS) have also been reported with inherited CC exclusively. The principal eye anomalies correspond to microcornea, aniridia, microphthalmia, or vitreoretinal dysplasia.

\section{IRE, GALK1 and GCNT2}

The hyperferritinaemia-cataract syndrome (OMIM 600886), an autosomal dominant condition, presents high serum ferritin levels and bilateral CCs. Mutations in the I-ferritin gene that encodes the iron-responsive element (IRE) results in hyperferritinaemia-cataract syndrome
(http://www.hgmd.cf.ac.uk/ac/gene.php?gene=FTL). The IRE in the ferritin mRNAs is a structure in the $5^{\prime}$-untranslated region. The increase of iron diminishes the binding of trans-acting iron-regulatory proteins with the ferritin mRNA structure, resulting in increased ferritin mRNA translation. Mutations in the IRE block this IRE-mediated regulation of ferritin production with the subsequent hyperferritinemia [Brooks et al., 2002]; this gene defect produces CC. Galactokinase 1 converts galactose into galactose-1-phosphate, when galactokinase deficiency is present, the accumulating galactose is converted to galactitol by aldose reductase and the cataractogenesis is observed. In this case, only CC with no other manifestations is present (Table 3). The human blood $i$ and I antigens are linear and branched repeats of $\mathrm{N}$-acetyllactosamine, respectively. The I-branching beta-1,6-N-acetylglucosaminyltransferase enzyme catalyzes the conversion of the i to the I antigen. Null phenotype of I (the adult i phenotype) is associated with CC. The gene defect in the I locus leads to the formation of CC with no other clinical manifestations (Table 3).

\section{Diagnosis of Inherited Cataracts}

As previously described, hereditary CC is a difficult condition to diagnose genetically due to more than 100 genes that have been associated with it. This task is even more difficult if no specific inherited pattern is observed in the pedigree. When systemic anomalies are present in the clinical symptomatology, syndromic cataracts are a possible diagnosis. The presence of cataracts with no other alterations reduces the genes involved to 35 . Fortunately, the new molecular tools are very useful in identifying the gene affection with the support of clinical data. Next-generation sequencing (NGS) certainly represents an excellent tool for analyzing inherited cataracts. Some physicians believe the technique should not be used in cases of monogenic diseases due to high costs and the fact that it generates volumes of data which can be difficult to interpret. The analysis would be easier to interpret if the potentially affected gene is preselected. NGS enables identifying mutations throughout the human genome by facilitating the genetic diagnosis of hereditary diseases, of course including CCs, and has opened a new pathway in genetic diagnosis.

\section{Disclosure Statement}

The authors report no conflicts of interest. 


\section{References}

Addison PK, Berry V, Holden KR, Espinal D, Rivera $B$, et al: A novel mutation in the connexin 46 gene (GJA3) causes autosomal dominant zonular pulverulent cataract in a Hispanic family. Mol Vis 12:791-795 (2006).

Aldahmesh MA, Khan AO, Mohamed J, Alkuraya FS: Novel recessive BFSP2 and PITX3 mutations: insights into mutational mechanisms from consanguineous populations. Genet Med 11:978-981 (2011).

Aldahmesh MA, Khan AO, Mohamed JY, Hijazi $\mathrm{H}, \mathrm{Al}$-Owain $\mathrm{M}$, et al: Genomic analysis of pediatric cataract in Saudi Arabia reveals novel candidate disease genes. Genet Med 14:955962 (2012).

AlFadhli S, Abdelmoaty S, Al-Hajeri A, Behbehani A, Alkuraya F: Novel crystallin gamma B mutations in a Kuwaiti family with autosomal dominant congenital cataracts reveal genetic and clinical heterogeneity. Mol Vis 18:29312936 (2012).

Ali M, Buentello-Volante B, McKibbin M, RochaMedina JA, Fernandez-Fuentes N, et al: Homozygous FOXE3 mutations cause non-syndromic, bilateral, total sclerocornea, aphakia, microphthalmia and optic disc coloboma. Mol Vis 16:1162-1168 (2010).

Alizadeh A, Clark JI, Seeberger T, Hess J, Blankenship $\mathrm{T}$, et al: Targeted genomic deletion of the lens-specific intermediate filament protein CP49. Invest Ophthalmol Vis Sci 43:37223727 (2002).

Alizadeh A, Clark J, Seeberger T, Hess J, Blankenship T, FitzGerald PG: Targeted deletion of the lens fiber cell-specific intermediate filament protein filensin. Invest Ophthalmol Vis Sci 44:5252-5258 (2003).

Amato KR, Wang S, Hastings AK, Youngblood VM, Santapuram PR, et al: Genetic and pharmacologic inhibition of EPHA2 promotes apoptosis in NSCLC. J Clin Invest 124:20372049 (2014).

Anjum I, Eiberg H, Baig SM, Tommerup N, Hansen L: A mutation in the FOXE3 gene causes congenital primary aphakia in an autosomal recessive consanguineous Pakistani family. Mol Vis 16:549-555 (2010).

Apple DJ, Ram J, Foster A, Peng Q: Elimination of cataract blindness: a global perspective entering the new millenium. Surv Ophthalmol 45 Suppl 1:S1-196 (2000).

Arora A, Minogue PJ, Liu X, Reddy MA, Ainsworth JR, et al: A novel GJA8 mutation is associated with autosomal dominant lamellar pulverulent cataract: further evidence for gap junction dysfunction in human cataract. J Med Genet 43:e2 (2006).

Arora A, Minogue PJ, Liu X, Addison PK, RusselEggitt I, et al: A novel connexin50 mutation associated with congenital nuclear pulverulent cataracts. J Med Genet 45:155-160 (2008).

Asada M, Okano Y, Imamura T, Suyama I, Hase Y, Isshiki G: Molecular characterization of galactokinase deficiency in Japanese patients. J Hum Genet 44:377-382 (1999).
Augusteyn RC: On the growth and internal structure of human lens. Exp Eye Res 90:643-654 (2010).

Azuma N, Hirakiyama A, Inoue T, Asaka A, Yamada M: Mutations of a human homologue of the Drosophila eyes absent gene (EYA1) detected in patients with congenital cataracts and ocular anterior segment anomalies. Hum Mol Genet 9:363-366 (2000).

Bassnett S, Wilmarth PA, David LL: The membrane proteome of the mouse lens fiber cell. Mol Vis 15:2448-2463 (2009).

Bateman JB, Geyer DD, Flodman P, Johannes M, Sikela J, et al: A new betaA1-crystallin splice junction mutation in autosomal dominant cataract. Invest Ophthalmol Vis Sci 41:32783285 (2000).

Bateman JB, von-Bischhoffshaunsen FR, Richter L, Flodman P, Burch D, Spence MA: Gene conversion mutation in crystallin, beta-B2 (CRYBB2) in a Chilean family with autosomal dominant cataract. Ophthalmology 114:425432 (2007).

Beby F, Commeaux C, Bozon M, Denis P, Edery P, Morlé L: New phenotype associated with an Arg116Cys mutation in the CRYAA gene: nuclear cataract, iris coloboma, and microphthalmia. Arch Ophthalmol 125:213-216 (2007).

Behnam M, Imagawa E, Chaleshtori AR, Ronasian F, Salehi M, et al: A novel homozygous mutation in HSF4 causing autosomal recessive congenital cataract. J Hum Genet 61:177-179 (2016).

Bennett TM, Shiels A: A recurrent missense mutation in GJA3 associated with autosomal dominant cataract linked to chromosome 13q. Mol Vis 17:2255-2262 (2011).

Bennett TM, Mackay DS, Knopf HL, Shiels A: A novel missense mutation in the gene for gapjunction protein alpha3 (GJA3) associated with autosomal dominant "nuclear punctate" cataracts linked to chromosome 13q. Mol Vis 10:376-382 (2004)

Bennett TM, Mackay DS, Siegfried CJ, Shiels A: Mutation of the melastatin-related cation channel, TRPM3, underlies inherited cataract and glaucoma. PLoS One 9:e104000 (2014).

Berry V, Mackay D, Khaliq S, Francis PJ, Hameed A, et al: Connexin 50 mutation in a family with congenital "zonular nuclear" pulverulent cataract of Pakistani origin. Hum Genet 105:168170 (1999).

Berry V, Francis P, Kaushal S, Moore A, Bhattacharya S: Missense mutations in MIP underlie autosomal dominant "polymorphic" and lamellar cataracts linked to $12 \mathrm{q}$. Nat Genet 25: 15-17 (2000).

Berry V, Francis P, Reddy MA, Collyer D, Vithana $\mathrm{E}$, et al: Alpha-B crystallin gene (CRYAB) mutation causes dominant congenital posterior polar cataract in humans. Am J Hum Genet 69:1141-1145 (2001)

Berry V, Gregory-Evans C, Emmett W, Waseem $\mathrm{N}$, Raby J, et al: Wolfram gene (WFS1) mutation causes autosomal dominant congenital nuclear cataract in humans. Eur J Hum Genet 21:1356-1360 (2013).

Bhishagratna K: An English translation of the SushrutaSamshitá: Based on original Sanskrit text, with a full and comprehensive introduction, additional texts, different readings, notes, comparative views, index, glossary and plates, in Chowkhamba Sanskrit Series Office, vol 3:XVII, pp 206-210 (Calcutta, Varanasi 2005).

Billingsley G, Santhiya ST, Paterson AD, Ogata K, Wodak S, et al: CRYBA4, a novel human cataract gene, is also involved in microphthalmia. Am J Hum Genet 79:702-709 (2006).

Boon CJ, Klevering BJ, Leroy BP, Hoyng CB, Keunen JE, den Hollander AI: The spectrum of ocular phenotypes caused by mutations in the BEST1 gene. Prog Retin Eye Res 28:187205 (2009).

Boone PM, Yuan B, Gu S, Ma Z, Gambin T, et al: Hutterite-type cataract maps to chromosome 6p21.32-p21.31, cosegregates with a homozygous mutation in LEMD2, and is associated with sudden cardiac death. Mol Genet Genomic Med 4:77-94 (2015).

Borck G, Kakar N, Hoch J, Friedrich K, Freudenberg J, et al: An Alu repeat-mediated genomic GCNT2 deletion underlies congenital cataracts and adult i blood group. Hum Genet 131: 209-216 (2012).

Brémond-Gignac D, Bitoun P, Reis LM, Copin H, Murray JC, Semina EV: Identification of dominant FOXE3 and PAX6 mutations in patients with congenital cataract and aniridia. Mol Vis 16:1705-1711 (2010).

Brennan LA, Kantorow WL, Chauss D, McGreal $\mathrm{R}, \mathrm{He} \mathrm{S}$, et al: Spatial expression patterns of autophagy genes in the eye lens and induction of autophagy in lens cells. Mol Vis 18:17731786 (2012).

Broooks DG, Manova-Todorova K, Farmer J, Lobmayr L, Wilson RB, et al: Ferritin crystal cataracts in hereditary hyperferritinemia cataract syndrome. Invest Ophthalmol Vis Sci 43: 1121-1126 (2002).

Bu J, He S, Wang L, Li J, Liu J, Zhang X: A novel splice donor site mutation in EPHA2 caused congenital cataract in a Chinese family. Indian J Ophthalmol 64:364-368 (2016).

Bu L, Jin Y, Shi Y, Chu R, Ban A, Eiberg H, et al: Mutant DNA-binding domain of HSF4 is associated with autosomal dominant lamellar and Marner cataract. Nat Genet 31:276-278 (2002).

Burdon KP, Wirth MG, Mackey DA, RussellEggitt IM, Craig JE, et al: A novel mutation in the Connexin 46 gene causes autosomal dominant congenital cataract with incomplete penetrance. J Med Genet 41:e106 (2004).

Bykhovskaya Y, Caiado Canedo AL, Wright KW, Rabinowitz YS: C.57C $>\mathrm{T}$ mutation in $M I R$ 184 is responsible for congenital cataracts and corneal abnormalities in a five-generation family from Galicia, Spain. Ophthalmic Genet 36:244-247 (2015). 
Chacon-Camacho OF, Buentello-Volante B, Velázquez-Montoya R, Ayala-Ramirez R, Zenteno JC: Homozygosity mapping identifies a GALK1 mutation as the cause of autosomal recessive congenital cataracts in 4 adult siblings. Gene 534:218-221 (2014).

Chance B: Clio Medica: A Series of Primers on the History of Medicine, vol XX, Krumbhaar EB (ed), Cloth (Paul B. Hoeber Inc., New York 1939).

Chen C, Sun Q, Gu M, Liu K, Sun Y, Xu X: A novel Cx50 (GJA8) p.H277Y mutation associated with autosomal dominant congenital cataract identified with targeted next-generation sequencing. Graefes Arch Clin Exp Ophthalmol 253:915-924 (2015).

Chen J, Ma Z, Jiao X, Fariss R, Kantorow WL, et al: Mutations in FYCO1 cause autosomal-recessive congenital cataracts. Am J Hum Genet 88:827-838 (2011).

Chen JH, Qiu J, Chen H, Pang CP, Zhang M: Rapid and cost-effective molecular diagnosis using exome sequencing of one proband with autosomal dominant congenital cataract. Eye (Lond) 28:1511-1516 (2014)

Chen JH, Huang C, Zhang B, Yin S, Liang J, et al: Mutations of RagA GTPase in mTORC1 pathway are associated with autosomal dominant cataracts. PLoS Genet 12:e1006090 (2016).

Chen Q, Ma J, Yan M, Mothobi ME, Liu Y, Zheng F: A novel mutation in CRYAB associated with autosomal dominant congenital nuclear cataract in a Chinese family. Mol Vis 15:13591365 (2009).

Chen W, Chen X, Hu Z, Lin H, Zhou F, et al: A missense mutation in CRYBB2 leads to progressive congenital membranous cataract by impacting the solubility and function of $\beta \mathrm{B} 2$ crystallin. PLoS One 8:e81290 (2013).

Clark AR, Lubsen NH, Slingsby C: sHSP in the eye lens: crystallin mutations, cataract and proteostasis. Int J Biochem Cell Biol 44:1687-1697 (2012).

Coccia M, Brooks SP, Webb TR, Christodoulou $\mathrm{K}$, Wozniak IO, et al: X-linked cataract and Nance-Horan syndrome are allelic disorders. Hum Mol Genet 18:2643-2655 (2009).

Cohen D, Bar-Yosef U, Levy J, Gradstein L, Belfair $\mathrm{N}$, et al: Homozygous CRYBB1 deletion mutation underlies autosomal recessive congenital cataract. Invest Ophthalmol Vis Sci 48:22082213 (2007).

Conley YP, Erturk D, Keverline A, Mah TS, Keravala $\mathrm{A}$, et al: A juvenile-onset, progressive cataract locus on chromosome $3 \mathrm{q} 21-\mathrm{q} 22$ is associated with a missense mutation in the beaded filament structural protein-2. Am J Hum Genet 66:1426-1431 (2000).

Cui X, Gao L, Jin Y, Zhang Y, Bai J, et al: The E233del mutation in BFSP2 causes a progressive autosomal dominant congenital cataract in a Chinese family. Mol Vis13:2023-2029 (2007).

Dave A, Laurie K, Staffieri SE, Taranath D, Mackey DA, et al: Mutations in the EPHA2 gene are a major contributor to inherited cataracts in South-Eastern Australia. PLoS One 8:e72518 (2013).
Devi RR, Vijayalakshmi P: Novel mutations in GJA8 associated with autosomal dominant congenital cataract and microcornea. Mol Vis 12:190-195 (2006).

Devi RR, Reena C, Vijayalakshmi P: Novel mutations in GJA3 associated with autosomal dominant congenital cataract in the Indian population. Mol Vis 11:846-852 (2005).

Devi RR, Yao W, Vijayalakshmi P, Sergeev YV, Sundaresan P, Hejtmancik JF: Crystallin gene mutations in Indian families with inherited pediatric cataract. Mol Vis 14:1157-1170 (2008).

Ding X, Wang B, Luo Y, Hu S, Zhou G, et al: A novel mutation in the connexin 46 (GJA3) gene associated with congenital cataract in a Chinese pedigree. Mol Vis 17:1343-1349 (2011).

Ding X, Zhou N, Lin H, Chen J, Zhao C, et al: A novel MIP gene mutation analysis in a Chinese family affected with congenital progressive punctate cataract. PLoS One 9:e102733 (2014).

Doucette L, Green J, Fernandez B, Johnson GJ, Parfrey P, Young TL: A novel, non-stop mutation in FOXE3 causes an autosomal dominant form of variable anterior segment dysgenesis including Peters anomaly. Eur J Hum Genet 19:293-299 (2011).

Edwards AO: Clinical features of the congenital vitreoretinopathies. Eye (Lond) 22:1233-1242 (2008).

Eiberg H, Lund AM, Warburg M, Rosenberg T: Assignment of congenital cataract Volkmann type (CCV) to chromosome 1p36. Hum Genet 96:33-38 (1995)

Faletra F, d'Adamo AP, Pensiero S, Athanasakis E, Catalano D, et al: A novel CRYBB2 missense mutation causing congenital autosomal dominant cataract in an Italian family. Ophthalmic Genet 34:115-117 (2013).

Ferda Percin E, Ploder LA, Yu JJ, Arici K, Horsford DJ, et al: Human microphthalmia associated with mutations in the retinal homeobox gene CHX10. Nat Genet 25:397-401 (2000).

Ferrini W, Schorderet DF, Othenin-Girard P, Uffer S, Héon E, Munier FL: CRYBA3/A1 gene mutation associated with suture-sparing autosomal dominant congenital nuclear cataract: a novel phenotype. Invest Ophthalmol Vis Sci 45:1436-1441 (2004)

Florijn RJ, Loves W, Maillette de Buy WennigerPrick LJ, Mannens MM, Tijmes N, et al: New mutations in the NHS gene in Nance-Horan Syndrome families from the Netherlands. Eur J Hum Genet 14:986-990 (2006).

Forshew T, Johnson CA, Khaliq S, Pasha S, Willis $\mathrm{C}$, et al: Locus heterogeneity in autosomal recessive congenital cataracts: linkage to $9 \mathrm{q}$ and germline HSF4 mutations. Hum Genet 117: 452-459 (2005).

Gao J, Wang H, Sun X, Varadaraj K, Li L, et al: The effects of age on lens transport. Invest Ophthalmol Vis Sci 54:7174-7187 (2013).

Gao M, Huang S, Li J, Zou Y, Xu P, et al: A novel pathogenic mutation of $C R Y G D$ gene in a congenital cataract family (in Chinese). Zhonghua Yi Xue Yi Chuan Xue Za Zhi 4:515-518 (2016).
Gao X, Cheng J, Lu C, Li X, Li F, et al: A novel mutation in the connexin 50 gene (GJA8) associated with autosomal dominant congenital nuclear cataract in a Chinese family. Curr Eye Res 35:597-604 (2010).

Garnai SJ, Huyghe JR, Reed DM, Scott KM, Liebmann JM, et al: Congenital cataracts: de novo gene conversion event in CRYBB2. Mol Vis 20:1579-1593 (2014).

Ge XL, Zhang Y, Wu Y, Lv J, Zhang W, et al: Identification of a novel GJA8 (Cx50) point mutation causes human dominant congenital cataracts. Sci Rep 4:4121 (2014).

Geyer DD, Spence MA, Johannes M, Flodman P, Clancy KP, et al: Novel single-base deletional mutation in major intrinsic protein $(M I P)$ in autosomal dominant cataract. Am J Ophthalmol 141:761-763 (2006).

Gilbert C, Foster A: Childhood blindness in the context of VISION 2020 - the right to sight. Bull World Health Organ 79:227-232 (2001).

Gill D, Klose R, Munier FL, McFadden M, Priston $\mathrm{M}$, et al: Genetic heterogeneity of the Coppock-like cataract: a mutation in $C R Y B B 2$ on chromosome 22q11.2. Invest Ophthalmol Vis Sci 41:159-165 (2000).

Gillespie RL, O'Sullivan J, Ashworth J, Bhaskar S, Williams S, et al: Personalized diagnosis and management of congenital cataract by nextgeneration sequencing. Ophthalmology 121: 2124-2137 (2014)

Gong X, Li E, Klier G, Huang Q, Wu Y, et al: Disruption of alpha3 connexin gene leads to proteolysis and cataractogenesis in mice. Cell 91: 833-843 (1997).

Gonzalez-Huerta LM, Messina-Baas OM, CuevasCovarrubias SA: A family with autosomal dominant primary congenital cataract associated with a CRYGC mutation: evidence of clinical heterogeneity. Mol Vis 13:1333-1338 (2007).

Gradstein L, Zolotushko J, Sergeev YV, Lavy I, Narkis G, et al: Novel GUCY2D mutation causes phenotypic variability of Leber congenital amaurosis in a large kindred. BMC Med Genet 17:52 (2016).

Graw J, Klopp N, Illig T, Preising MN, Lorenz B: Congenital cataract and macular hypoplasia in humans associated with a de novo mutation in CRYAA and compound heterozygous mutations in P. Graefes Arch Clin Exp Ophthalmol 244:912-919 (2006).

Graw J, Schmidt W, Minogue PJ, Rodriguez J, Tong JJ, et al: The GJA8 allele encoding CX50I247M is a rare polymorphism, not a cataract-causing mutation. Mol Vis 15:18811885 (2009).

Greenlees R, Mihelec M, Yousoof S, Speidel D, Wu SK, et al: Mutations in SIPA1L3 cause eye defects through disruption of cell polarity and cytoskeleton organization. Hum Mol Genet 24:5789-5804 (2015).

Gu F, Li R, Ma XX, Shi LS, Huang SZ, Ma X: A missense mutation in the gammaD-crystallin gene CRYGD associated with autosomal dominant congenital cataract in a Chinese family. Mol Vis 12:26-31 (2006). 
Gu F, Zhai H, Li D, Zhao L, Li C, et al: A novel mutation in major intrinsic protein of the lens gene $(M I P)$ underlies autosomal dominant cataract in a Chinese family. Mol Vis 13:16511656 (2007).

Gu F, Luo W, Li X, Wang Z, Lu S, et al: A novel mutation in AlphaA-crystallin (CRYAA) caused autosomal dominant congenital cataract in a large Chinese family. Hum Mutat 29: 769 (2008)

Gu J, Qi Y, Wang L, Wang J, Shi L, et al: A new congenital nuclear cataract caused by a missense mutation in the gammaD-crystallin gene (CRYGD) in a Chinese family. Mol Vis 11:971-976 (2005).

Gu Z, Ji B, Wan C, He G, Zhang J, et al: A splice site mutation in CRYBA1/A3 causing autosomal dominant posterior polar cataract in a Chinese pedigree. Mol Vis 16:154-160 (2010).

Guleria K, Sperling K, Singh D, Varon R, Singh JR, Vanita V: A novel mutation in the connexin 46 (GJA3) gene associated with autosomal dominant congenital cataract in an Indian family. Mol Vis 13:1657-1665 (2007).

Guo Y, Su D, Li Q, Yang Z, Ma Z, et al: A nonsense mutation of CRYGC associated with autosomal dominant congenital nuclear cataracts and microcornea in a Chinese pedigree. Mol Vis 18:1874-1880 (2012).

Guo Y, Yuan L, Yi J, Xiao J, Xu H, et al: Identification of a GJA3 mutation in a Chinese family with congenital nuclear cataract using exome sequencing. Indian J Biochem Biophys 50: 253-258 (2013).

Hansen L, Yao W, Eiberg H, Funding M, Riise R, et al: The congenital 'ant-egg' cataract phenotype is caused by a missense mutation in connexin46. Mol Vis 12:1033-1039 (2006).

Hansen L, Eiberg H, Rosenberg T: Novel MAF mutation in a family with congenital cataractmicrocornea syndrome. Mol Vis 13:20192022 (2007).

Hansen L, Mikkelsen A, Nürnberg P, Nürnberg G, Anjum I, et al: Comprehensive mutational screening in a cohort of Danish families with hereditary congenital cataract. Invest Ophthalmol Vis Sci 50:3291-3303 (2009).

Hansen L, Comyn S, Mang Y, Lind-Thomsen A, Myhre L, et al: The myosin chaperone UNC45B is involved in lens development and autosomal dominant juvenile cataract. Eur J Hum Genet 22:1290-1297 (2014).

Happ H, Weh E, Costakos D, Reis LM, Semina $\mathrm{EV}$ : Case report of homozygous deletion involving the first coding exons of GCNT2 isoforms $A$ and $B$ and part of the upstream region of TFAP2A in congenital cataract. BMC Med Genet 17:64 (2016)

He W, Li X, Chen J, Xu L, Zhang F, et al: Genetic linkage analyses and $C x 50$ mutation detection in a large multiplex Chinese family with hereditary nuclear cataract. Ophthalmic Genet 32:48-53 (2011).

Hejtmancik JF, Smaoui N: Molecular genetics of cataract. Dev Ophthalmol 37:67-82 (2003).

Héon E, Priston M, Schorderet DF, Billingsley GD, Girard PO, et al: The gamma-crystallins and human cataracts: a puzzle made clearer. Am J Hum Genet 65:1261-1277 (1999).

Héon E, Paterson AD, Fraser M, Billingsley G, Priston $\mathrm{M}$, et al: A progressive autosomal recessive cataract locus maps to chromosome 9q13-q22. Am J Hum Genet 68:772-777 (2001).

Hoehenwarter W, Klose J, Jungblut PR: Eye lens proteomics. Amino Acids 30:369-389 (2006).

Hu S, Wang B, Zhou Z, Zhou G, Wang J, et al: A novel mutation in GJA8 causing congenital cataract-microcornea syndrome in a Chinese pedigree. Mol Vis 16:1585-1592 (2010).

Hu Y, Gao L, Feng Y, Yang T, Huang S, et al: Identification of a novel mutation of the gene for gap junction protein $\alpha 3$ (GJA3) in a Chinese family with congenital cataract. Mol Biol Rep 41:4753-4758 (2014).

Hunter M, Angelicheva D, Levy HL, Pueschel SM, Kalaydjieva L: Novel mutations in the GALK1 gene in patients with galactokinase deficiency. Hum Mutat 17:77-78 (2001).

Iliff BW, Riazuddin SA, Gottsch JD: A single-base substitution in the seed region of miR-184 causes EDICT syndrome. Invest Ophthalmol Vis Sci 53:348-353 (2012).

Inaba $\mathrm{N}$, Hiruma $\mathrm{T}$, Togayachi $\mathrm{A}$, Iwasaki $\mathrm{H}$, Wang XH, et al: A novel I-branching beta-1,6$\mathrm{N}$-acetylglucosaminyltransferase involved in human blood group I antigen expression. Blood 101:2870-2876 (2003).

Iseri SU, Osborne RJ, Farrall M, Wyatt AW, Mirza G, et al: Seeing clearly: the dominant and recessive nature of FOXE3 in eye developmental anomalies. Hum Mutat 30:1378-1386 (2009).

Jakobs PM, Hess JF, FitzGerald PG, Kramer P, Weleber RG, Litt M: Autosomal-dominant congenital cataract associated with a deletion mutation in the human beaded filament protein gene BFSP2. Am J Hum Genet 66:14321436 (2000).

Jamieson RV, Perveen R, Kerr B, Carette M, Yardley J, et al: Domain disruption and mutation of the bZIP transcription factor, MAF, associated with cataract, ocular anterior segment dysgenesis and coloboma. Hum Mol Genet 11:33-42 (2002).

Jamieson RV, Farrar N, Stewart K, Perveen R, Mihelec $\mathrm{M}$, et al: Characterization of a familial $t(16 ; 22)$ balanced translocation associated with congenital cataract leads to identification of a novel gene, TMEM114, expressed in the lens and disrupted by the translocation. Hum Mutat 28:968-977 (2007).

Javadiyan S, Craig JE, Souzeau E, Sharma S, Lower KM, et al: Recurrent mutation in the crystallin alpha A gene associated with inherited paediatric cataract. BMC Res Notes 9:83 (2016).

Jia X, Zhang F, Bai J, Gao L, Zhang X, et al: Combinational analysis of linkage and exome sequencing identifies the causative mutation in a Chinese family with congenital cataract. BMC Med Genet 14:107 (2013).

Jiang $\mathrm{H}$, Jin $\mathrm{Y}, \mathrm{Bu} \mathrm{L}$, Zhang $\mathrm{W}$, Liu J, Cui B, et al: A novel mutation in GJA3 (connexin46) for autosomal dominant congenital nuclear pulverulent cataract. Mol Vis 9:579-583 (2003).

Jiang J, Jin C, Wang W, Tang X, Shentu X, et al: Identification of a novel splice-site mutation in MIP in a Chinese congenital cataract family. Mol Vis 15:38-44 (2009).

Jiaox X, Khan SY, Irum B, Khan AO, Wang Q, et al: Missense mutations in CRYAB are liable for recessive congenital cataracts. PLoS One 10:e0137973 (2015).

Kalaydjieva L, Perez-Lezaun A, Angelicheva D, Onengut $\mathrm{S}$, Dye $\mathrm{D}$, et al: A founder mutation in the GK1 gene is responsible for galactokinase deficiency in Roma (Gypsies). Am J Hum Genet 65:1299-1307 (1999).

Kamachi Y, Uchikawa M, Tanouchi A, Sekido R, Kondoh H: Pax6 and SOX2 form a co-DNAbinding partner complex that regulates initiation of lens development. Genes Dev 15:12721286 (2001).

Kannabiran C, Rogan PK, Olmos L, Basti S, Rao GN, et al: Autosomal dominant zonular cataract with sutural opacities is associated with a splice mutation in the betaA3/A1-crystallin gene. Mol Vis 4:21 (1998).

Kannan R, Sreekumar PG, Hinton DR: Novel roles for alpha-crystallins in retinal function and disease. Prog Retin Eye Res 31:576-604 (2012).

Kaul H, Riazuddin SA, Shahid M, Kousar S, Butt $\mathrm{NH}$, et al: Autosomal recessive congenital cataract linked to EPHA2 in a consanguineous Pakistani family. Mol Vis 16:511-517 (2010)

Ke T, Wang QK, Ji B, Wang X, Liu P, et al: Novel HSF4 mutation causes congenital total white cataract in a Chinese family. Am J Ophthalmol 142:298-303 (2006).

Khan AO, Aldahmesh MA, Meyer B: Recessive congenital total cataract with microcornea and heterozygote carrier signs caused by a novel missense CRYAA mutation (R54C). Am J Ophthalmol 144:949-952 (2007).

Khan AO, Aldahmesh MA, Ghadhfan FE, AlMesfer S, Alkuraya FS: Founder heterozygous P23T CRYGD mutation associated with cerulean (and coralliform) cataract in 2 Saudi families. Mol Vis 15:1407-1411 (2009).

Khan AO, Aldahmesh MA, Mohamed JY, Alkuraya FS: Clinical and molecular analysis of children with central pulverulent cataract from the Arabian Peninsula. Br J Ophthalmol 96: 650-655 (2012).

Khan AO, Aldahmesh MA, Alkuraya FS: Phenotypes of recessive pediatric cataract in a cohort of children with identified homozygous gene mutations (An American Ophthalmological Society Thesis). Trans Am Ophthalmol Soc 113:T7 (2015).

Kmoch S, Brynda J, Asfaw B, Bezouska K, Novák $\mathrm{P}$, et al: Link between a novel human gammaDcrystallin allele and a unique cataract phenotype explained by protein crystallography. Hum Mol Genet 9:1779-1786 (2000).

Kolosha V, Anoia E, de Cespedes C, Gitzelmann $\mathrm{R}$, Shih L, et al: Novel mutations in 13 probands with galactokinase deficiency. Hum Mutat 15:447-453 (2000). 
Kondo Y, Saitsu H, Miyamoto T, Lee BJ, Nishiyama $\mathrm{K}$, et al: Pathogenic mutations in two families with congenital cataract identified with whole-exome sequencing. Mol Vis 19: 384-389 (2013).

Kondoh H, Uchikawa M, Kamachi Y: Interplay of Pax6 and SOX2 in lens development as a paradigm of genetic switch mechanisms for cell differentiation. Int J Dev Biol 48:819-827 (2004).

Kong XD, Liu N, Shi HR, Dong JM, Zhao ZH, et al: A novel 3-base pair deletion of the CRYAA gene identified in a large Chinese pedigree featuring autosomal dominant congenital perinuclear cataract. Genet Mol Res 14:426-432 (2015).

Kumar M, Agarwal T, Khokhar S, Kumar M, Kaur $\mathrm{P}$, et al: Mutation screening and genotype phenotype correlation of $\alpha$-crystallin, $\gamma$-crystallin and GJA8 gene in congenital cataract. Mol Vis 17:693-707 (2011).

Lachke SA, Alkuraya FS, Kneeland SC, Ohn T, Aboukhalil A, et al: Mutations in the RNA granule component TDRD7 cause cataract and glaucoma. Science 331:1571-1576 (2011).

Laurie KJ, Dave A, Straga T, Souzeau E, Chataway $\mathrm{T}$, et al: Identification of a novel oligomerization disrupting mutation in CRYAA associated with congenital cataract in a South Australian family. Hum Mutat 34:435-438 (2013).

Li B, Liu Y, Liu Y, Guo H, Hu Z, et al: Identification of a GJA3 mutation in a large family with bilateral congenital cataract. DNA Cell Biol 35:135-139 (2016).

Li D, Wang S, Ye H, Tang Y, Qiu X, et al: Distribution of gene mutations in sporadic congenital cataract in a Han Chinese population. Mol Vis 22:589-598 (2016).

Li FF, Zhu SQ, Wang SZ, Gao C, Huang SZ, et al: Nonsense mutation in the CRYBB2 gene causing autosomal dominant progressive polymorphic congenital coronary cataracts. Mol Vis 14:750-755 (2008).

Li FF, Yang M, Ma X, Zhang Q, Zhang M, et al: Autosomal dominant congenital nuclear cataracts caused by a CRYAA gene mutation. Curr Eye Res 35:492-498 (2010).

Li J, Wang Q, Fu Q, Zhu Y, Zhai Y, et al: A novel connexin 50 gene (gap junction protein, alpha 8 ) mutation associated with congenital nuclear and zonular pulverulent cataract. Mol Vis 19:767-774 (2013).

Li XQ, Cai HC, Zhou SY, Yang JH, Xi YB, et al: A novel mutation impairing the tertiary structure and stability of $\gamma \mathrm{C}$-crystallin (CRYGC) leads to cataract formation in humans and zebrafish lens. Hum Mutat 2:391-401 (2012).

Li Y, Wang J, Dong B, Man H: A novel connexin46 (GJA3) mutation in autosomal dominant congenital nuclear pulverulent cataract. Mol Vis 10:668-671 (2004).

Liang C, Liang H, Yang Y, Ping L, Jie Q: Mutation analysis of two families with inherited congenital cataracts. Mol Med Rep 12:3469-3475 (2015).

Lin H, Hejtmancik JF, Qi Y: A substitution of arginine to lysine at the $\mathrm{COOH}$-terminus of MIP caused a different binocular phenotype in a congenital cataract family. Mol Vis 13:18221827 (2007).

Lin Y, Liu NN, Lei CT, Fan YC, Liu XQ, et al: A novel GJA8 mutation in a Chinese family with autosomal dominant congenital cataract (in Chinese). Zhonghua Yi Xue Yi Chuan Xue Za Zhi 25:59-62 (2008).

Litt M, Carrero-Valenzuela R, LaMorticella DM, Schultz DW, Mitchell TN, et al: Autosomal dominant cerulean cataract is associated with a chain termination mutation in the human beta-crystallin gene CRYBB2. Hum Mol Genet 6:665-668 (1997).

Litt M, Kramer P, LaMorticella DM, Murphey W, Lovrien EW, Weleber RG: Autosomal dominant congenital cataract associated with a missense mutation in the human alpha crystallin gene CRYAA. Hum Mol Genet 7:471-474 (1998).

Liu BF, Liang JJ: Confocal fluorescence microscopy study of interaction between lens MIP26/ AQP0 and crystallins in living cells. J Cell Biochem 104:51-58 (2008).

Liu J, Xu J, Gu S, Nicholson BJ, Jiang JX: Aquaporin 0 enhances gap junction coupling via its cell adhesion function and interaction with connexin 50. J Cell Sci 124:198-206 (2011).

Liu L, Zhang Q, Zhou LX, Tang ZH: A novel HSF4 mutation in a Chinese family with autosomal dominant congenital cataract. J Huazhong Univ Sci Technolog Med Sci 35:316-318 (2015).

Liu Q, Wang KJ, Zhu SQ: A novel p.G112E mutation in BFSP2 associated with autosomal dominant pulverulent cataract with sutural opacities. Curr Eye Res 39:1013-1019 (2014).

Liu Y, Zhang X, Luo L, Wu M, Zeng R, et al: A novel alphaB-crystallin mutation associated with autosomal dominant congenital lamellar cataract. Invest Ophthalmol Vis Sci 47:10691075 (2006).

Lou D, Tong JP, Zhang LY, Chiang SW, Lam DS, Pang CP: A novel mutation in CRYBB2 responsible for inherited coronary cataract. Eye (Lond) 23:1213-1220 (2009).

Lovicu FJ, Overbeek PA: Overlapping effects of different members of the FGF family on lens fiber differentiation in transgenic mice. Development 125:3365-3377 (1998).

Lu S, Zhao C, Jiao H, Kere J, Tang X, et al: Two Chinese families with pulverulent congenital cataracts and deltaG91 CRYBA1 mutations. Mol Vis 13:1154-1160 (2007).

Lv H, Huang C, Zhang J, Liu Z, Zhang Z, et al: A novel HSF4 gene mutation causes autosomaldominant cataracts in a Chinese family. G3 (Bethesda) 4:823-828 (2014).

Ma AS, Grigg JR, Ho G, Prokudin I, Farnsworth E, et al: Sporadic and familial congenital cataracts: mutational spectrum and new diagnoses using next-generation sequencing. Hum $\mathrm{Mu}$ tat 37:371-384 (2016).

Ma J, Becker C, Reyes C, Underhill DM: Cutting edge: FYCO1 recruitment to dectin-1 phagosomes is accelerated by light chain 3 protein and regulates phagosome maturation and re- active oxygen production. J Immunol 192: 1356-1360 (2014)

Ma MF, Li LB, Pei YQ, Cheng Z: Use of highthroughput targeted exome sequencing in genetic diagnosis of Chinese family with congenital cataract. Int J Ophthalmol 9:650-654 (2016).

Ma X, Li FF, Wang SZ, Gao C, Zhang M, Zhu SQ: A new mutation in BFSP2 (G1091A) causes autosomal dominant congenital lamellar cataracts. Mol Vis 14:1906-1911 (2008).

Ma ZW, Zheng JQ, Li J, Li XR, Tang X, et al: Two novel mutations of connexin genes in Chinese families with autosomal dominant congenital nuclear cataract. Br J Ophthalmol 89:15351537 (2005).

Mackay D, Ionides A, Kibar Z, Rouleau G, Berry $\mathrm{V}$, et al: Connexin 46 mutations in autosomal dominant congenital cataract. Am J Hum Genet 64:1357-1364 (1999).

Mackay DS, Andley UP, Shiels A: Cell death triggered by a novel mutation in the alphaA-crystallin gene underlies autosomal dominant cataract linked to chromosome 21q. Eur J Hum Genet 11:784-793 (2003).

Mackay DS, Andley UP, Shiels A: A missense mutation in the gammaD crystallin gene (CRYGD) associated with autosomal dominant 'coral-like' cataract linked to chromosome 2q. Mol Vis 10:155-162 (2004).

Mackay DS, Bennett TM, Culican SM, Shiels A: Exome sequencing identifies novel and recurrent mutations in GJA8 and CRYGD associated with inherited cataract. Hum Genomics 8:19 (2014).

Marner E, Rosenberg T, Eiberg H: Autosomal dominant congenital cataract: morphology and genetic mapping. Acta Ophthalmol (Copenh) 67:151-158 (1989).

Martinez-Wittinghan FJ, Sellitto C, White TW, Mathias RT, Paul D, Goodenough DA: Lens gap junctional coupling is modulated by connexin identity and the locus of gene expression. Invest Ophthalmol Vis Sci 45:3629-3637 (2004).

McAvoy JW, Chamberlain CG: Fibroblast growth factor (FGF) induces different responses in lens epithelial cells depending on its concentration. Development 107:221-228 (1989).

Messina-Baas OM, Gonzalez-Huerta LM, CuevasCovarrubias SA: Two affected siblings with nuclear cataract associated with a novel missense mutation in the CRYGD gene. Mol Vis 12:995-1000 (2006).

Messina-BaasOM, Gonzalez-Garay ML, GonzálezHuerta LM, Toral-López J, Cuevas-Covarrubias SA: Whole exome sequencing reveals a mutation in CRYBB2 in a large Mexican family with autosomal dominant pulverulent cataract. Mol Syndromol 7:87-92 (2016).

Meyer E, Rahman F, Owens J, Pasha S, Morgan $\mathrm{NV}$, et al: Initiation codon mutation in betaB1-crystallin (CRYBB1) associated with autosomal recessive nuclear pulverulent cataract. Mol Vis 15:1014-1019 (2009).

Miao H, Wang B: Eph/ephrin signaling in epithelial development and homeostasis. Int J Biochem Cell Biol 41:762-770 (2009). 
Min HY, Qiao PP, Asan, Yan ZH, Jiang HF, et al: Targeted genes sequencing identified a novel 15 bp deletion on GJA8 in a Chinese family with autosomal dominant congenital cataracts. Chin Med J (Engl) 129:860-867 (2016).

Mothobi ME, Guo S, Liu Y, Chen Q, Yussuf AS, et al: Mutation analysis of congenital cataract in a Basotho family identified a new missense allele in CRYBB2. Mol Vis 15:1470-1475 (2009).

Müller M, Bhattacharya SS, Moore T, Prescott Q, Wedig $\mathrm{T}$, et al: Dominant cataract formation in association with a vimentin assembly disrupting mutation. Hum Mol Genet 18:10521057 (2009).

Nandrot E, Slingsby C, Basak A, Cherif-Chefchaouni M, Benazzouz B, et al: Gamma-D crystallin gene (CRYGD) mutation causes autosomal dominant congenital cerulean cataracts. J Med Genet 40:262-267 (2003).

Narumi Y, Nishina S, Tokimitsu M, Aoki Y, Kosaki R, et al: Identification of a novel missense mutation of $M A F$ in a Japanese family with congenital cataract by whole exome sequencing: a clinical report and review of literature. Am J Med Genet A 164A:1272-1276 (2014).

Nettleship E, Ogilvie FM: A peculiar form of hereditary congenital cataract. Trans Ophthal Soc UK 26:191-206 (1906).

Ormestad M, Blixt A, Churchill A, Martinsson T, Enerbäck S, Carlsson P: Foxe3 haploinsufficiency in mice: a model for Peters' anomaly. Invest Ophthalmol Vis Sci 43:1350-1357 (2002).

Pankiv S, Alemu EA, Brech A, Bruun JA, Lamark T, et al: FYCO1 is a Rab7 effector that binds to LC3 and PI3P to mediate microtubule plus end-directed vesicle transport. Cell Biol 188: 253-269 (2010).

Park JE, Son AI, Zhou R: Roles of EphA2 in development and disease. Genes (Basel) 4:334-357 (2013).

Pasquale EB: Eph receptors and ephrins in cancer: bidirectional signalling and beyond. Nat Rev Cancer 10:165-180 (2010).

Pauli S, Söker T, Klopp N, Illig T, Engel W, Graw $\mathrm{J}$ : Mutation analysis in a German family identified a new cataract-causing allele in the CRYBB2 gene. Mol Vis 13:962-967 (2007).

Plotnikova OV, Kondrashov FA, Vlasov PK, Grigorenko AP, Ginter EK, Rogaev EI: Conversion and compensatory evolution of the gamma-crystallin genes and identification of a cataractogenic mutation that reverses the sequence of the human CRYGD gene to an ancestral state. Am J Hum Genet 81:32-43 (2007).

Polyakov AV, Shagina IA, Khlebnikova OV, Evgrafov OV: Mutation in the connexin 50 gene (GJA8) in a Russian family with zonular pulverulent cataract. Clin Genet 60:476-478 (2001).

Ponnam SP, Ramesha K, Tejwani S, Ramamurthy B, Kannabiran C: Mutation of the gap junction protein alpha 8 (GJA8) gene causes autosomal recessive cataract. J Med Genet 44:e85 (2007).

Ponnam SP, Ramesha K, Tejwani S, Matalia J, Kannabiran C: A missense mutation in LIM2 causes autosomal recessive congenital cataract. Mol Vis 14:1204-1208 (2008).

Ponnam SP, Ramesha K, Matalia J, Tejwani S, Ramamurthy B, Kannabiran C: Mutational screening of Indian families with hereditary congenital cataract. Mol Vis 19:1141-1148 (2013).

Pras E, Frydman M, Levy-Nissenbaum E, Bakhan $\mathrm{T}, \mathrm{Raz}$ J, et al: A nonsense mutation (W9X) in CRYAA causes autosomal recessive cataract in an inbred Jewish Persian family. Invest Ophthalmol Vis Sci 41:3511-3515 (2000).

Pras E, Raz J, Yahalom V, Frydman M, Garzozi HJ, et al: A nonsense mutation in the glucosaminyl (N-acetyl) transferase 2 gene (GCNT2): association with autosomal recessive congenital cataracts. Invest Ophthalmol Vis Sci 45:19401945 (2004).

Prokudin I, Simons C, Grigg JR, Storen R, Kumar $\mathrm{V}$, et al: Exome sequencing in developmental eye disease leads to identification of causal variants in GJA8, CRYGC, PAX6 and CYP1B1. Eur J Hum Genet 22:907-915 (2014).

Qi Y, Jia H, Huang S, Lin H, Gu J, et al: A deletion mutation in the betaA1/A3 crystallin gene (CRYBA1/A3) is associated with autosomal dominant congenital nuclear cataract in a Chinese family. Hum Genet 114:192-197 (2004).

Qin L, Guo L, Wang H, Li T, Lou G, et al: A novel MIP mutation in familial congenital nuclear cataracts. Eur J Med Genet 59:488-491 (2016).

Ramachandran RD, Perumalsamy V, Hejtmancik JF: Autosomal recessive juvenile onset cataract associated with mutation in BFSP1. Hum Genet 121:475-482 (2007).

Ramprasad VL, Thool A, Murugan S, Nancarrow $\mathrm{D}$, Vyas $\mathrm{P}$, et al: Truncating mutation in the NHS gene: phenotypic heterogeneity of Nance-Horan syndrome in an Asian Indian family. Invest Ophthalmol Vis Sci 46:17-23 (2005).

Reddy MA, Bateman OA, Chakarova C, Ferris J, Berry V, et al: Characterization of the G91del CRYBA1/3-crystallin protein: a cause of human inherited cataract. Hum Mol Genet 13: 945-953 (2004).

Rees MI, Watts P, Fenton I, Clarke A, Snell RG, et al: Further evidence of autosomal dominant congenital zonular pulverulent cataracts linked to 13q11 (CZP3) and a novel mutation in connexin 46 (GJA3). Hum Genet 106:206209 (2000).

Reich S, Hennermann J, Vetter B, Neumann LM, Shin YS, et al: An unexpectedly high frequency of hypergalactosemia in an immigrant Bosnian population revealed by newborn screening. Pediatr Res 51:598-601 (2002).

Reis LM, Tyler RC, Schneider A, Bardakjian T, Stoler JM, et al: FOXE3 plays a significant role in autosomal recessive microphthalmia. Am J Med Genet A 152A:582-590 (2010).

Reis LM, Tyler RC, Muheisen S, Raggio V, Salviati $\mathrm{L}$, et al: Whole exome sequencing in dominant cataract identifies a new causative factor, CRYBA2, and a variety of novel alleles in known genes. Hum Genet 132:761-770 (2013).
Reis LM, Tyler RC, Semina EV: Identification of a novel C-terminal extension mutation in EPHA2 in a family affected with congenital cataract. Mol Vis 20:836-842 (2014).

Ren Z, Li A, Shastry BS, Padma T, Ayyagari R, et al: A 5-base insertion in the gammaC-crystallin gene is associated with autosomal dominant variable zonular pulverulent cataract. Hum Genet 106:531-537 (2000).

Riazuddin SA, Yasmeen A, Yao W, Sergeev YV, Zhang Q, et al: Mutations in betaB3-crystallin associated with autosomal recessive cataract in two Pakistani families. Invest Ophthalmol Vis Sci 46:2100-2106 (2005).

Richardson JS: beta-Sheet topology and the relatedness of proteins. Nature 268:495-500 (1977).

Richter L, Flodman P, Barria F, Burch D, Brown S, et al: Clinical variability of autosomal dominant cataract, microcornea and corneal opacity and novel mutation in the alpha A crystallin gene (CRYAA). Am J Med Genet A 146A:833-842 (2008).

Roshan M, Vijaya PH, Lavanya GR, Shama PK, Santhiya ST, et al: A novel human CRYGD mutation in a juvenile autosomal dominant cataract. Mol Vis 16:887-896 (2010).

Safieh LA, Khan AO, Alkuraya FS: Identification of a novel CRYAB mutation associated with autosomal recessive juvenile cataract in a Saudi family. Mol Vis 15:980-984 (2009).

Sajjad N, Goebel I, Kakar N, Cheema AM, Kubisch C, Ahmad J: A novel HSF4 gene mutation (p.R405X) causing autosomal recessive congenital cataracts in a large consanguineous family from Pakistan. BMC Med Genet 9:99 (2008).

Santana A, Waiswol M, Arcieri ES, Cabral de Vasconcellos JP, Barbosa de Melo M: Mutation analysis of CRYAA, CRYGC, and CRYGD associated with autosomal dominant congenital cataract in Brazilian families. Mol Vis 15:793800 (2009).

Santhiya ST, Shyam M, Rawlley D, Vijayalakshmi $\mathrm{P}$, Namperumalsamy $\mathrm{P}$, et al: Novel mutations in the gamma-crystallin genes cause autosomal dominant congenital cataracts. J Med Genet 39:352-358 (2002).

Santhiya ST, Manisastry SM, Rawlley D, Malathi $\mathrm{R}$, Anishetty S, et al: Mutation analysis of congenital cataracts in Indian families: identification of SNPS and a new causative allele in $C R Y B B 2$ gene. Invest Ophthalmol Vis Sci 45: 3599-3607 (2004).

Santhiya ST, Soker T, Klopp N, Illig T, Prakash $\mathrm{MV}$, et al: Identification of a novel, putative cataract-causing allele in CRYAA (G98R) in an Indian family. Mol Vis 12:768-737 (2006).

Santhiya ST, Kumar GS, Sudhakar P, Gupta N, Klopp N, et al: Molecular analysis of cataract families in India: new mutations in the CRYBB2 and GJA3 genes and rare polymorphisms. Mol Vis 16:1837-1847 (2010).

Schmidt W, Klopp N, Illig T, Graw J: A novel GJA8 mutation causing a recessive triangular cataract. Mol Vis 14:851-856 (2008). 
Semina EV, Brownell I, Mintz-Hittner HA, Murray JC, Jamrich M: Mutations in the human forkhead transcription factor FOXE3 associated with anterior segment ocular dysgenesis and cataracts. Hum Mol Genet 10:231-236 (2001).

Senthil Kumar G, Kyle JW, Minogue PJ, Dinesh Kumar K, Vasantha K, et al: An MIP/AQP0 mutation with impaired trafficking and function underlies an autosomal dominant congenital lamellar cataract. Exp Eye Res 110: 136-141 (2013).

Sharma S, Burdon KP, Dave A, Jamieson RV, Yaron $\mathrm{Y}$, et al: Novel causative mutations in patients with Nance-Horan syndrome and altered localization of the mutant NHS-A protein isoform. Mol Vis 14:1856-1864 (2008).

Shentu X, Yao K, Xu W, Zheng S, Hu S, Gong X: Special fasciculiform cataract caused by a mutation in the gammaD-crystallin gene. Mol Vis 10:233-239 (2004).

Shentu X, Zhao SJ, Zhang L, Miao Q: A novel p.R890C mutation in EPHA2 gene associated with progressive childhood posterior cataract in a Chinese family. Int J Ophthalmol 6:34-38 (2013).

Shentu X, Miao Q, Tang X, Yin H, Zhao Y: Identification and functional analysis of a novel MIP gene mutation associated with congenital cataract in a Chinese family. PLoS One 10: e0126679 (2015).

Shiels A, Mackay D, Ionides A, Berry V, Moore A, Bhattacharya S: A missense mutation in the human connexin 50 gene (GJA8) underlies autosomal dominant "zonular pulverulent" cataract, on chromosome 1q. Am J Hum Genet 62: 526-532 (1998).

Shiels A, Bassnett S, Varadaraj K, Mathias R, AlGhoul K, et al: Optical dysfunction of the crystalline lens in aquaporin-0-deficient mice. Physiol Genomics 7:179-186 (2001).

Shiels A, Bennett TM, Knopf HL, Yamada K, Yoshiura $\mathrm{K}$, et al: $C H M P 4 B$, a novel gene for autosomal dominant cataracts linked to chromosome 20q. Am J Hum Genet 81:596-606 (2007).

Shiels A, Bennett TM, Knopf HL, Maraini G, Li A, et al: The EPHA2 gene is associated with cataracts linked to chromosome $1 \mathrm{p}$. Mol Vis 14: 2042-2055 (2008).

Shiels A, Bennett TM, Hejtmancik JF: Cat-Map: putting cataract on the map. Mol Vis 16:20072015 (2010).

Singh R, Ram J, Kaur G, Prasad R: Galactokinase deficiency induced cataracts in Indian infants: identification of 4 novel mutations in GALK gene. Curr Eye Res 37:949-954 (2012).

Slingsby C, Wistow GJ, Clark AR: Evolution of crystallins for a role in the vertebrate eye lens. Protein Sci 22:367-380 (2013).

Smaoui N, Beltaief O, BenHamed S, M'Rad R, Maazoul F, et al: A homozygous splice mutation in the HSF4 gene is associated with an autosomal recessive congenital cataract. Invest Ophthalmol Vis Sci 45:2716-2721 (2004).

Song Z, Wang L, Liu Y, Xiao W: A novel nonsense mutation in the MIP gene linked to congenital posterior polar cataracts in a Chinese family. PLoS One 10:e0119296 (2015).

Stambolian D, Ai Y, Sidjanin D, Nesburn K, Sathe $\mathrm{G}$, et al: Cloning of the galactokinase cDNA and identification of mutations in two families with cataracts. Nat Genet 10:307-312 (1995).

Stephan DA, Gillanders E, Vanderveen D, FreasLutz D, Wistow G, et al: Progressive juvenileonset punctate cataracts caused by mutation of the gammaD-crystallin gene. Proc Natl Acad Sci USA 96:1008-1012 (1999).

Su D, Guo Y, Li Q, Guan L, Zhu S, Ma X: A novel mutation in CRYAA is associated with autosomal dominant suture cataracts in a Chinese family. Mol Vis 18:3057-3063 (2012).

Su D, Yang Z, Li Q, Guan L, Zhang H, et al: Identification and functional analysis of GJA8 mutation in a Chinese family with autosomal dominant perinuclear cataracts. PLoS One 8: e59926 (2013).

Sun H, Ma Z, Li Y, Liu B, Li Z, et al: Gamma-S crystallin gene (CRYGS) mutation causes dominant progressive cortical cataract in humans. J Med Genet 42:706-710 (2005).

Sun W, Xiao X, Li S, Guo X, Zhang Q: Mutational screening of six genes in Chinese patients with congenital cataract and microcornea. Mol Vis 17:1508-1513 (2011a).

Sun W, Xiao X, Li S, Guo X, Zhang Q: Mutation analysis of 12 genes in Chinese families with congenital cataracts. Mol Vis 17:2197-2206 (2011b).

Sun W, Xiao X, Li S, Guo X, Zhang Q: Exome sequencing of 18 Chinese families with congenital cataracts: a new sight of the NHS gene. PLoS One 9:e100455 (2014).

Valleix S, Niel F, Nedelec B, Algros MP, Schwartz $\mathrm{C}$, et al: Homozygous nonsense mutation in the FOXE3 gene as a cause of congenital primary aphakia in humans. Am J Hum Genet 79:358-364 (2006).

Vanita V, Singh D: A missense mutation in $C R Y G D$ linked with autosomal dominant congenital cataract of aculeiform type. Mol Cell Biochem 368:167-172. (2012).

Vanita V, Sarhadi V, Reis A, Jung M, Singh D, et al: A unique form of autosomal dominant cataract explained by gene conversion between beta-crystallin B2 and its pseudogene. J Med Genet 38:392-396 (2001).

Vanita V, Singh D, Robinson PN, Sperling K, Singh JR: A novel mutation in the DNA-binding domain of MAF at 16q23.1 associated with autosomal dominant "cerulean cataract" in an Indian family. Am J Med Genet A 140:558566 (2006).

Vanita V, Singh JR, Singh D, Varon R, Sperling K: A mutation in GJA8 (p.P88Q) is associated with "balloon-like" cataract with Y-sutural opacities in a family of Indian origin. Mol Vis 14:1171-1175 (2008).

Vanita V, Singh JR, Singh D, Varon R, Sperling K: Novel mutation in the gamma-S crystallin gene causing autosomal dominant cataract. Mol Vis 15:476-481 (2009).

Wang $\mathrm{H}$, Zhang T, Wu D, Zhang J: A novel beaded filament structural protein 1 (BFSP1) gene mutation associated with autosomal dominant congenital cataract in a Chinese family. Mol Vis 19:2590-2595 (2013).

Wang J, Ma X, Gu F, Liu NP, Hao XL, et al: A missense mutation S228P in the CRYBB1 gene causes autosomal dominant congenital cataract. Chin Med J (Engl) 120:820-824 (2007).

Wang KJ, Zhu SQ: A novel p.F206I mutation in Cx46 associated with autosomal dominant congenital cataract. Mol Vis 18:968-973 (2012).

Wang KJ, Li SS, Yun B, Ma WX, Jiang TG, Zhu SQ: A novel mutation in MIP associated with congenital nuclear cataract in a Chinese family. Mol Vis 17:70-77 (2011a).

Wang KJ, Wang BB, Zhang F, Zhao Y, Ma X, Zhu SQ: Novel beta-crystallin gene mutations in Chinese families with nuclear cataracts. Arch Ophthalmol 129:337-343 (2011b).

Wang L, Lin H, Gu J, Su H, Huang S, Qi Y: Autosomal-dominant cerulean cataract in a Chinese family associated with gene conversion mutation in beta-B2-crystallin. Ophthalmic Res 41:148-153 (2009)

Wang L, Luo Y, Wen W, Zhang S, Lu Y: Another evidence for a D47N mutation in GJA8 associated with autosomal dominant congenital cataract. Mol Vis 17:2380-2385 (2011).

Wang L, Chen Y, Chen X, Sun X: Further evidence for P59L mutation in GJA3 associated with autosomal dominant congenital cataract. Indian J Ophthalmol 64:508-512 (2016).

Wang W, Jiang J, Zhu Y, Li J, Jin C, et al: A novel mutation in the major intrinsic protein (MIP) associated with autosomal dominant congenital cataracts in a Chinese family. Mol Vis 16: 534-539 (2010).

Weisschuh N, Aisenbrey S, Wissinger B, Riess A: Identification of a novel CRYBB2 missense mutation causing congenital autosomal dominant cataract. Mol Vis 18:174-180 (2012).

Willoughby CE, Arab S, Gandhi R, Zeinali S, Arab $\mathrm{S}$, et al: A novel GJA8 mutation in an Iranian family with progressive autosomal dominant congenital nuclear cataract. J Med Genet 40:e124 (2003)

Willoughby CE, Shafiq A, Ferrini W, Chan LL, Billingsley $\mathrm{G}$, et al: $C R Y B B 1$ mutation associated with congenital cataract and microcornea. Mol Vis 11:587-593 (2005).

Wu Q, Shi H, Liu N, Lu N, Jiang M, et al: Mutation analysis of CRYBB1 gene and prenatal diagnosis for a Chinese kindred featuring autosomal dominant congenital nuclear cataract (in Chinese). Zhonghua Yi Xue Yi Chuan Xue Za Zhi 30:266-269 (2013).

Wussuki-Lior O, Abu-Horowitz A, Netzer I, Almer Z, Morad Y, et al: Hematologic biomarkers in childhood cataracts. Mol Vis 17:10111015 (2011).

Xia XY, Li N, Cao X, Wu QY, Li TF, et al: A novel COL4A1 gene mutation results in autosomal dominant non-syndromic congenital cataract in a Chinese family. BMC Med Genet 15:97 (2014a). 
Xia XY, Wu QY, An LM, Li WW, Li N, et al: A novel P20R mutation in the alpha-B crystallin gene causes autosomal dominant congenital posterior polar cataracts in a Chinese family. BMC Ophthalmol 14:108 (2014b).

Xiao X, Li W, Wang P, Li L, Li S, et al: Cerulean cataract mapped to $12 \mathrm{q} 13$ and associated with a novel initiation codon mutation in MIP. Mol Vis 17:2049-2055 (2011).

Xu WZ, Zheng S, Xu SJ, Huang W, Yao K, Zhang SZ: Autosomal dominant coralliform cataract related to a missense mutation of the gammaD-crystallin gene. Chin Med J (Engl) 117: 727-732 (2004).

Yan M, Xiong C, Ye SQ, Chen Y, Ke M, et al: A novel connexin 50 (GJA8) mutation in a Chinese family with a dominant congenital pulverulent nuclear cataract. Mol Vis 14:418-424 (2008).

Yang G, Xing B, Liu G, Lu X, Jia X, et al: A novel mutation in the GJA3 (connexin46) gene is associated with autosomal dominant congenital nuclear cataract in a Chinese family. Mol Vis 17:1070-1073 (2011a).

Yang G, Zhang G, Wu Q, Zhao J: A novel mutation in the MIP gene is associated with autosomal dominant congenital nuclear cataract in a Chinese family. Mol Vis 17:1320-1323 (2011b).

Yang G, Chen Z, Zhang W, Liu Z, Zhao J: Novel mutations in CRYGD are associated with congenital cataracts in Chinese families. Sci Rep 6:18912 (2016)

Yang J, Zhu Y, Gu F, He X, Cao Z, et al: A novel nonsense mutation in CRYBB1 associated with autosomal dominant congenital cataract. Mol Vis 14:727-731 (2008).

Yang J, Li D, Fan Q, Cai L, Qiu X, et al: The polymorphisms with cataract susceptibility impair the EPHA2 receptor stability and its cytoprotective function. J Ophthalmol 2015: 401894 (2015).

Yang Z, Li Q, Ma Z, Guo Y, Zhu S, Ma X: A G $\rightarrow$ T splice site mutation of $C R Y B A 1 / A 3$ associated with autosomal dominant suture cataracts in a Chinese family. Mol Vis 17:2065-2071 (2011).

Yang Z, Su D, Li Q, Yang F, Ma Z, et al: A novel $\mathrm{T} \rightarrow \mathrm{G}$ splice site mutation of $C R Y B A 1 / A 3$ associated with autosomal dominant nuclear cataracts in a Chinese family. Mol Vis 18: 1283-1288 (2012).

Yang Z, Su D, Li Q, Ma Z, Yang F, et al: A R54L mutation of CRYAA associated with autosomal dominant nuclear cataracts in a Chinese family. Curr Eye Res 38:1221-1228 (2013).

Yang Z, Li Q, Ma X, Zhu SQ: Mutation analysis in Chinese families with autosomal dominant hereditary cataracts. Curr Eye Res 40:12251231 (2015).

Yao K, Tang X, Shentu X, Wang K, Rao H, Xia K: Progressive polymorphic congenital cataract caused by a CRYBB2 mutation in a Chinese family. Mol Vis 11:758-763 (2005).
Yao K, Jin C, Zhu N, Wang W, Wu R, et al: A nonsense mutation in CRYGC associated with autosomal dominant congenital nuclear cataract in a Chinese family. Mol Vis 14:1272-1276 (2008).

Yao K, Li J, Jin C, Wang W, Zhu Y, et al: Characterization of a novel mutation in the CRYBB2 gene associated with autosomal dominant congenital posterior subcapsular cataract in a Chinese family. Mol Vis 17:144-152 (2011a).

Yao K, Wang W, Zhu Y, Jin C, Shentu X, et al: A novel GJA3 mutation associated with congenital nuclear pulverulent and posterior polar cataract in a Chinese family. Hum Mutat 32: 1367-1370. (2011b).

Yasmeen A, Riazuddin SA, Kaul H, Mohsin S, Khan M, et al: Autosomal recessive congenital cataract in consanguineous Pakistani families is associated with mutations in GALK1. Mol Vis 16:682-688 (2010).

Yu LC, Twu YC, Chang CY, Lin M: Molecular basis of the adult i phenotype and the gene responsible for the expression of the human blood group I antigen. Blood 98:3840-3845 (2001).

Yu Y, Li J, Xu J, Wang Q, Yu Y, Yao K: Congenital polymorphic cataract associated with a $\mathrm{G}$ to $\mathrm{A}$ splice site mutation in the human beta-crystallin gene $C R Y \beta A 3 / A 1$. Mol Vis 18:2213-2220 (2012).

Yu Y, Yu Y, Chen P, Li J, Zhu Y, et al: A novel MIP gene mutation associated with autosomal dominant congenital cataracts in a Chinese family. BMC Med Genet 15:6 (2014).

Yu Y, Wu M, Chen X, Zhu Y, Gong X, Yao K: Identification and functional analysis of two novel connexin 50 mutations associated with autosome dominant congenital cataracts. Sci Rep 6:26551 (2016).

Yuan L, Guo Y, Yi J, Xiao J, Yuan J, et al: Identification of a novel GJA3 mutation in congenital nuclear cataract. Optom Vis Sci 92:337-342 (2015).

Yuan L, Yi J, Lin Q, Xu H, Deng X, et al: Identification of a PRX variant in a Chinese family with congenital cataract by exome sequencing. QJM 109:731-735 (2016).

Zeng L, Liu W, Feng W, Wang X, Dang H, et al: A novel donor splice-site mutation of major intrinsic protein gene associated with congenital cataract in a Chinese family. Mol Vis 19:22442249 (2013).

Zenteno JC, Morales ME, Moran-Barroso V, Sanchez-Navarro A: CRYGD gene analysis in a family with autosomal dominant congenital cataract: evidence for molecular homogeneity and intrafamilial clinical heterogeneity in aculeiform cataract. Mol Vis 11:438-442 (2005).

Zhai Y, Li J, Zhu Y, Xia Y, Wang W, et al: A nonsense mutation of $\gamma \mathrm{D}$-crystallin associated with congenital nuclear and posterior polar cataract in a Chinese family. Int J Med Sci 11: 158-163 (2014).

Zhang J, Zhang Y, Fang F, Mu W, Zhang N, et al: Congenital cataracts due to a novel 2-bp deletion in CRYBA1/A3. Mol Med Rep 10:16141618 (2014).
Zhang L, Gao L, Li Z, Qin W, Gao W, et al: Progressive sutural cataract associated with a BFSP2 mutation in a Chinese family. Mol Vis 12:1626-1631 (2006).

Zhang L, Qu X, Su S, Guan L, Liu P: A novel mutation in GJA3 associated with congenital Coppock-like cataract in a large Chinese family. Mol Vis 18:2114-2118 (2012).

Zhang LY, Yam GH, Fan DS, Tam PO, Lam DS, Pang CP: A novel deletion variant of gam$\mathrm{maD}$-crystallin responsible for congenital nuclear cataract. Mol Vis 13:2096-2104 (2007).

Zhang LY, Yam GH, Tam PO, Lai RY, Lam DS, et al: An alphaA-crystallin gene mutation, Arg12Cys, causing inherited cataract-microcornea exhibits an altered heat-shock response. Mol Vis 15:1127-1138 (2009a).

Zhang LY, Gong B, Tong JP, Fan DS, Chiang SW, et al: A novel gammaD-crystallin mutation causes mild changes in protein properties but leads to congenital coralliform cataract. $\mathrm{Mol}$ Vis 15:1521-1529 (2009b).

Zhang Q, Guo X, Xiao X, Yi J, Jia X, Hejtmancik JF: Clinical description and genome wide linkage study of Y-sutural cataract and myopia in a Chinese family. Mol Vis 10:890-900 (2004).

Zhao H, Brown PH, Magone MT, Schuck P: The molecular refractive function of lens $\gamma$ crystallins. J Mol Biol 411:680-699 (2011).

Zhao L, Chen XJ, Zhu J, Xi YB, Yang X, et al: Lanosterol reverses protein aggregation in cataracts. Nature 523:607-611 (2015).

Zheng JQ, Ma ZW, Sun HM: A heterozygous transversion of connexin 50 in a family with congenital nuclear cataract in the northeast of China (in Chinese). Zhonghua Yi Xue Yi Chuan Xue Za Zhi 22:76-78 (2005).

Zhou D, Ji H, Wei Z, Guo L, Li Y, et al: A novel insertional mutation in the connexin 46 (gap junction alpha 3 ) gene associated with autosomal dominant congenital cataract in a Chinese family. Mol Vis 19:789-795 (2013).

Zhou G, Zhou N, Hu S, Zhao L, Zhang C, Qi Y: A missense mutation in CRYBA4 associated with congenital cataract and microcornea. Mol Vis 16:1019-1024 (2010).

Zhou Z, Hu S, Wang B, Zhou N, Zhou S, et al: Mutation analysis of congenital cataract in a Chinese family identified a novel missense mutation in the connexin 46 gene (GJA3). Mol Vis 16:713-719 (2010).

Zhu Y, Shentu X, Wang W, Li J, Jin C, Yao K: A Chinese family with progressive childhood cataracts and IVS3+1G $>$ A CRYBA3/A1 mutations. Mol Vis 16:2347-2353 (2010).

Zhu Y, Yu H, Wang W, Gong X, Yao K: A novel GJA8 mutation (p.V44A) causing autosomal dominant congenital cataract. PLoS One 9: e115406 (2014).

Zhuang X, Wang L, Song Z, Xiao W: A novel insertion variant of $C R Y G D$ is associated with congenital nuclear cataract in a Chinese family. PLoS One 10:e0131471 (2015). 